\title{
Electron Beam Melting of Ti-6Al-4V Lattice Structures; Correlation between Post Heat Treatment and Mechanical Properties
}

\section{Giuseppe Del Guercio}

Department of Management and Production Engineering (DIGEP), Politecnico di Torino, Manuela Galati

Department of Management and Production Engineering (DIGEP), Politecnico di Torino, Abdollah Saboori ( $\sim$ abdollah.saboori@polito.it)

Politecnico di Torino https://orcid.org/0000-0001-7135-1316

\section{Research Article}

Keywords: Additive Manufacturing, Electron Beam Melting, Lattice structures, Heat treatment

Posted Date: March 1st, 2021

DOI: https://doi.org/10.21203/rs.3.rs-248635/v1

License: (1) This work is licensed under a Creative Commons Attribution 4.0 International License. Read Full License

Version of Record: A version of this preprint was published at The International Journal of Advanced Manufacturing Technology on July 21st, 2021. See the published version at https://doi.org/10.1007/s00170-021-07619-w. 


\title{
Electron Beam Melting of Ti-6Al-4V Lattice Structures; Correlation between Post Heat Treatment and Mechanical properties
}

\author{
Giuseppe Del Guercio ${ }^{1}$, Manuela Galati ${ }^{1,2}$, Abdollah Saboori ${ }^{1,2, *}$ \\ ${ }^{1}$ Department of Management and Production Engineering (DIGEP), Politecnico di Torino, Corso Duca degli Abruzzi \\ 24, 10129 Torino, Italy. \\ ${ }^{3}$ Integrated Additive Manufacturing Center (IAM) @ Polito, Politecnico Di Torino, Corso Duca degli Abruzzi 24, \\ 10129 Torino, Italy. \\ * Corresponding Author; abdollah.saboori@polito.it, Phone: +39-0110907285
}

\begin{abstract}
Additive Manufacturing processes are considered advanced manufacturing methods. It would be possible to produce complex shape components from a Computer-Aided Design model in a layer-bylayer manner. Lattice structures as one of the complex geometries could attract lots of attention for both medical and industrial applications. In these structures, besides cell size and cell type, the microstructure of lattice structures can play a key role in these structures' mechanical performance. On the other hand, heat treatment has a significant influence on the mechanical properties of the material. Therefore, in this work, the effect of the heat treatments on the microstructure and mechanical behaviour of Ti-6Al-4V lattice structures manufactured by EBM was analyzed. The main mechanical properties were compared with the Ashby and Gibson model. It is very interesting to notice that a more homogeneous failure mode was found for the heat-treated samples. The structures' relative density was the main factor influencing their mechanical performance of the heat-treated samples. It is also found that the heat treatments were able to preserve the stiffness and the compressive strength of the lattice structures. Besides, an increment of both the elongation at failure and the absorbed energy was obtained after the heat treatments. Microstructure analysis of the heattreated samples confirms the increment of ductility of the heat-treated samples with respect to the asbuilt one.
\end{abstract}

Keywords: Additive Manufacturing, Electron Beam Melting, Lattice structures, Heat treatment

\section{Introduction}

Additive manufacturing (AM) is "a process of joining materials to obtain components from 3D model data using a layer upon layer approach" [1-3]. This approach enables the successful production of parts without design constraints, allowing the integration of components and the use of topologically optimized and lightweight structures $[4,5]$. Therefore, over the past years, various companies and 
industrial sectors have applied this technology to benefit from its advantages [6, 7]. In general, metal AM processes can be divided as follows: Directed Energy Deposition (DED) and Powder Bed Fusion $(\mathrm{PBF})$. Among the latter, the Electron Beam Melting (EBM) process has received considerable interest in the aerospace and medical sectors [7, 8]. The main driver for aerospace applications is represented by the possibility to process the materials that their processability with the other technologies faced with several challenges [9]. Regarding the medical sector, the EBM process is able to produce tailored implants, ensuring better bio-compatibility and improving the interaction between the prosthesis and prior tissues [10].

Ti-6Al-4V is one of the most processed materials by EBM technology, which can open new doors in the manufacturing of this particular alloy [11]. Traditionally, Ti-6Al-4V parts suffer from highdensity inclusions (HDI), low-density inclusions (LDI) and surface oxidation [12]. EBM process can avoid the first two defects mentioned above and limit the latter due to its vacuum working conditions [11]. On the other hand, during the production of Ti-6Al-4V alloy via the EBM process due to the presence of preheating phase before the melting, the temperature inside the building chamber reaches values of $650-750^{\circ} \mathrm{C}$ for this specific alloy $[11],[13,14]$. These working conditions ensure small thermal shrinkages and the powder bed results in enough strength to support the construction of the overhang part and limiting the use of supports [15]. Therefore, EBM makes possible the production of so-called micro-architectured components. These parts, also known as cellular structures, are of considerable interest because of the opportunity to achieve a singular combination of lightness and high mechanical properties compared to their corresponding bulk ones [16, 17]. In general, this class of materials includes foams and lattice structures [18]. Lattice structures are widely produced by EBM thanks to the possibility to achieve high specific strength [19], oxidation resistance [19, 20] and biocompatibility with the human tissues [10, 20, 21]. These structures, which are also known as cellular, reticulated or truss, have been defined as repetitions in the space of a unit elementary cell [16]. The three main factors affecting the properties of cellular solids that have been identified by Ashby [22] are: (1) the material of which is made, (2) the cell topology and shape, and (3) the relative density. The first affects the mechanical, electrical and thermal properties, while the second, following the Maxwell criterion [23], distinguishes bending-dominated structures from strength dominated structures. The relative density is given by the ratio between the density of the cellular material $\left(\rho^{*}\right)$ and the density of the bulk material $\left(\rho_{s}\right)$ [18]. The relative density and the unit cell's topology strongly affect both the cooling rate of the material during the solidification and the load distribution during its working conditions. High cooling rate values may lead to forming a microstructure mainly composed of $\alpha^{\prime}$ martensite, in contrast with the bulk material [13, 19, 24-31]. 
Up to date, several studies have been focused on evaluating the performance of lattice structures. For instance, Del Guercio et al. [32] have analyzed the mechanical performance of three different types of lattice structures: (i) Dode thin, (ii) G-Structure 3 and (iii) Rombi-Dodecahedron. The structures have been tested under compressive at room temperature in their work. According to Ashby and Gibson [18], the results showed that three main trends characterize the stress-strain trend: (1) elastic behaviour of the lattice structures (a linear segment), (2) progressive collapse of the layers up to the point where (3) the structure has the same behaviour of the bulk material. The limit of the elastic behaviour is the failure point, namely, when the stress reaches the Ultimate Compressive Strength $\left(U C S^{*}\right)$, and the strain reaches the elongation at failure $\left(A^{*}\right)$. Typically, the failure mode in these components is a brittle fracture at $45^{\circ}$, as reported in the literature [30-36]. The lattice structures manufactured in larger cell sizes showed the worst mechanical performances, in terms of both Young's modulus and $U C S^{*}$, with respect to those produced with smaller cell size $[32,35,37,38]$. Ashby and Gibson [18] proposed a model to describe the mechanical performances of lattice structures, in which a generic relative property (defined as the ratio between the selected property of the lattice structure by the corresponding one of the bulk) can be expressed, in a bi-logarithmic diagram, as a linear relationship of the lattice relative density. Thereafter, several studies have used the Ashby and Gibson's [18] model to fit their evaluated mechanical properties experimentally [18], [25], [40], [29]-[33], [37]-[39]. Additionally, Del Guercio et al. [32] proved that the absorbed energy up to failure $\left(W^{*}\right)$ also follows an Ashby-Gibson-like relationship. However, they also showed that the relative density is not totally descriptive of the mechanical behaviour of the lattice structure. All in all, several efforts have been made to evaluate the effect of cell type and cell size on the compressive behaviour of the EBM Ti-6Al-4V lattice structures. However, far too little attention has been paid to the effect of different heat-treatments on the mechanical properties of the EBM lattice structures. This can potentially open new opportunities and widen the range of application of Ti-6Al$4 \mathrm{~V}$ lattice structures. Several studies have shown the potential of the heat treatment on Ti-6Al-4V bulky parts. Several works proved that the overall porosity of the parts made by EBM could be reduced by applying a Hot Isostatic Pressing (HIP) treatment that is generally conducted at $920^{\circ} \mathrm{C}$ for $2 \mathrm{~h}[28,39-41]$. Tammas-Williams et al. [40] showed that the temperature in an annealing heat treatment enables the formation of new voids or pore regrowth during the heat treatment after HIP. De Formanoir et al. [25] showed that thermal cycles significantly affect the mechanical response of the bulk parts. They studied two different heat treatments: the first was conducted below $\beta$-transus (transition temperature between the $\alpha$ and $\beta$ phases is equal to $995^{\circ} \mathrm{C}$ [13]) at a specific temperature of $950^{\circ} \mathrm{C}$ for 60 minutes. On the other hand, the second one was conducted at $1040^{\circ} \mathrm{C}$ for a total time 
of 30 minutes. The results showed that at higher temperatures, the microstructure changed due to solid-state diffusion and coarsening of the plates of the $\alpha$ phase. As far as the response of lattice structure to heat treatment is concerned, far too little attention has been paid. As an example, Epasto et al. [42] studied the compressive behaviour of Ti-6Al-4V cellular structures manufactured by EBM, which were heat-treated to reduce residual stress. They concluded that the possible presence of residual stresses does not significantly affect the compressive behaviour of Ti-6Al-4V lattice structures manufactured by the EBM process. On the other side, in the topology optimization of the complex shape components a mix of lattice and bulk structures is generally used in order to reduce their weight keeping their mechanical performance as high as their fully bulk ones. Heat treatment is also found to be a very high efficient solution to improve their mechanical performance of the bulk materials. However, the effect of thermal treatment on the microstructure and mechanical features of the lattice parts of the topology optimized components is rarely considered. Therefore, the aim of the present study is to deeply analyse the effect of different heat treatments on the lattice structures. With this scope, the microstructure and mechanical properties of the Ti-6Al-4V lattice structures produced by EBM process in the as-built and heat-treated states are compared. Isothermal heat treatments were performed below and above the $\beta$-transus. Compressive tests at the ambient temperature are conducted with the aim to correlate the mechanical performance to the microstructure variation induced by the heat treatments.

\section{Materials and Methods}

\subsection{Lattice design and production}

In this work, the same lattice designs of our previous work were used to compare the response of the lattice structures in the as-built and heat-treated states [32]. For this reason, three different unit cell topologies were studied: (i) Dode thin, (ii) G-Structure 3 and (iii) Rombi-dodecahedron (Figure 1).

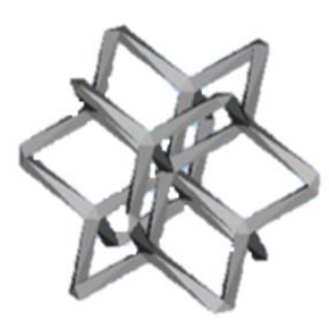

(a)

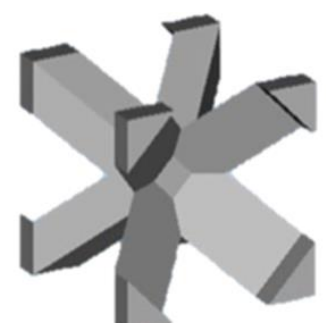

(b)

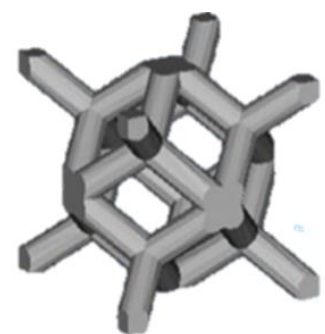

(c)

Figure 1. Unit cells used in the present work; (a) Structure I: dode thin, (b) Structure II: G-Structure 3, (c) Structure

III: Rombi Dodecahedron.

These structures were selected among the standard lattice unit cells presented in the Materialise Magics 21.11 software database. This choice enables the analysis of different relative densities and 
strut sizes. Compressive samples (Figure 2) were designed in a cylindrical shape with a diameter and $20 \mathrm{~mm}$ and $30 \mathrm{~mm}$ height, respectively.

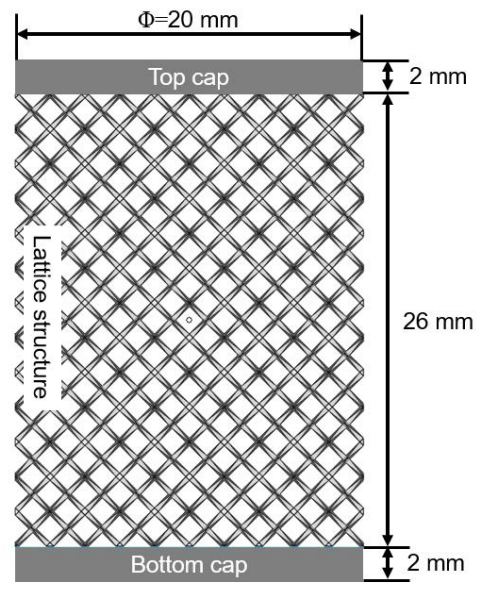

Figure 2. The general design of each specimen for the compression test.

The lattice structures were designed between two bulk caps with a thickness of $2 \mathrm{~mm}$ in order to provide a uniform distribution of the load during the compressive tests. As a result, the lattice segment's total height, without considering these disks, was $26 \mathrm{~mm}$. Each unit cell has been designed in three different sizes: 4, 7 and $10 \mathrm{~mm}$. With the specific aim to guarantee a robust experimental analysis, each cell typology and size were produced in three replicas. Since the overall thermal conditions analysed were three, 81 samples were produced in a single job. All the specimens were produced unattached to the start plate with the addition of support structures to avoid microstructure modifications. They were also spaced along the build direction axis to have a uniform temperature distribution during each build phase. The build job was prepared using Magics 21.11 and processed by the EBM build processor 5.0 with Ti-6Al-4V standard theme for the Arcam A2X system. The layer thickness was set equal to $50 \mu \mathrm{m}$. Standard Arcam Ti-6Al-4V powder with an average size of $75 \mu \mathrm{m}$ was used as a feedstock material to produce the lattice structures using an Arcam A2X system. The adopted process parameters are listed in Table 1.

Table 1. Process parameters used in this work to produce the lattice structures.

\begin{tabular}{|c|c|c|c|c|c|}
\hline & $\begin{array}{c}\text { Scan Speed } \\
{[\mathrm{mm} / \mathrm{s}]}\end{array}$ & $\begin{array}{c}\text { Focus Offset } \\
{[\mathrm{mA}]}\end{array}$ & $\begin{array}{c}\text { Max Beam } \\
\text { Current }[\mathrm{mA}]\end{array}$ & $\begin{array}{l}\text { Number of } \\
\text { contours }\end{array}$ & $\begin{array}{c}\text { Hatch contours } \\
{[\mathrm{mm}]}\end{array}$ \\
\hline Outer Contour & 450 & 0 & 3 & 1 & 0.13 \\
\hline Inner Contour & 470 & 0 & 3 & 1 & 0.13 \\
\hline
\end{tabular}

After the production, the entire build has been cooled down inside the Arcam A2X chamber. Subsequently, all the residual powder was removed from the samples using a blasting process with compressed air at 4 bar and the same Ti-6Al-4V powder used for the production.

\subsection{Heat treatments}


In order to track the effect of heat treatment temperature on the mechanical performance of the lattice structure, two different heat treatments, below and above the transus temperature, were performed. Figure 3 depicts the temperature-time cycle used in this work to heat treat the Ti-6Al-4V lattice structures. Both heat treatments were conducted for 60 minutes under vacuum to avoid oxidation at high temperatures. Both thermal cycles were performed with the same heating and cooling rates while the first heat treatment, named HT1 (blue line in Figure 3), was performed at $950^{\circ} \mathrm{C}$, below $\beta$-transus and the second heat treatment, named HT2 (red line in Figure 3), was performed at $1040^{\circ} \mathrm{C}$, above $\beta$ transus. The as-built condition was named as NTH.

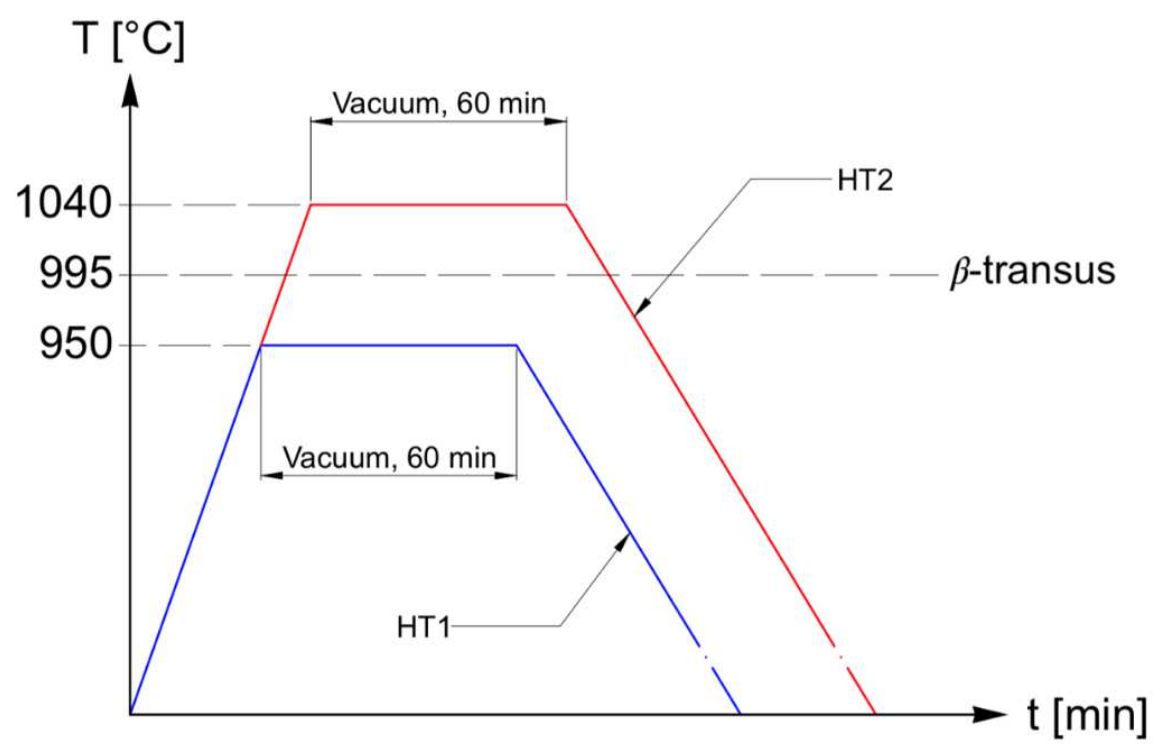

Figure 3. temperature-time curves for the designed thermal cycles.

\subsection{Compression Test}

Mechanical behaviour of the lattice structures is analysed under uniaxial compression tests using a strain velocity of $2 \mathrm{~mm} / \mathrm{min}$ up to the full collapse of the structure. In order to evaluate the stress/strain curves, loads and displacements were converted using Eq. 1 and Eq. 2:

$$
\begin{aligned}
\sigma & =\frac{P}{A_{0}} \\
\varepsilon & =\frac{\delta}{l_{0}}
\end{aligned}
$$

$P$ represents the load and $\delta$ is the displacement measured during the compression test; $A_{0}$ represents the area of the whole structure, namely the area of a $20 \mathrm{~mm}$ diameter circle; $l_{0}$ is the height of the lattice part of each sample $(26 \mathrm{~mm})$. Figure 4 depicts a qualitative stress/strain trend. 


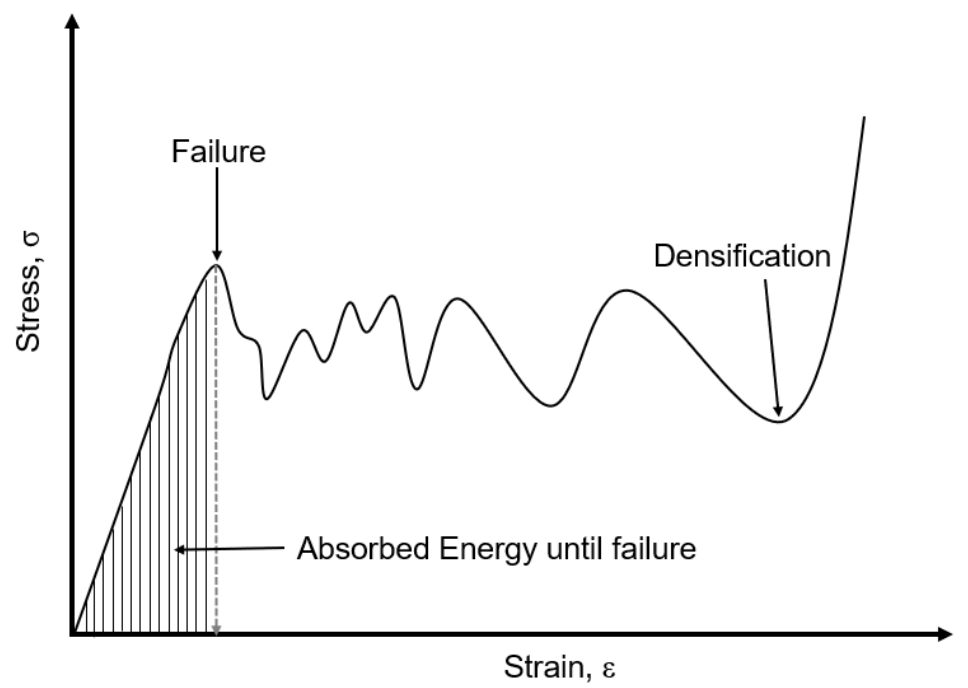

Figure 4. Qualitative stress/strain compressive trend of a generic lattice structure.

In a stress/strain diagram, the area under the curve and delimited by the failure point represents the absorbed energy up to failure per unit of volume. The total absorbed energy up to failure $\left(W^{*}\right)$ can be evaluated according to Eq. (3), where $V^{*}$ is the actual volume of a lattice structure.

$$
W^{*}=\int_{0}^{A^{*}} \sigma d \varepsilon \cdot V^{*}
$$

The compressive Young's modulus $\left(E^{*}\right)$ is represented by the slope of the linear trend (red line in Figure 4). Considering two points in this line, $E^{*}$ can be evaluated using Eq. (4).

$$
E^{*}=\frac{\sigma_{2}-\sigma_{1}}{\varepsilon_{2}-\varepsilon_{1}}
$$

\subsection{Characterization}

By the subtraction of the mass of the upper and bottom cup from the total weight of the sample, the relative density $\left(\rho * \rho_{s}\right)$ of each structure was evaluated from the ratio between the density of the lattice structure $\left(\rho^{*}\right)$ and the nominal density of the bulk material $\left(\rho_{s}\right)$. Table 2 lists the measured and calculated data for each cell topology and size.

Table 2. Average values of the weight of the lattice and relative densities.

\begin{tabular}{lccccccccc}
\hline Structure & \multicolumn{3}{c}{ I } & \multicolumn{1}{c}{ II } & \multicolumn{3}{c}{ III } \\
\hline Size $[\mathrm{mm}]$ & 4 & 7 & 10 & 4 & 7 & 10 & 4 & 7 & 10 \\
\hline $\mathrm{m}_{\text {latt }}[\mathrm{g}]$ & 5.832 & 3.139 & 2.018 & 12.016 & 7.512 & 6.806 & 10.298 & 9.697 & 8.887 \\
\hline$\rho^{*} / \rho_{\mathrm{s}}[\%]$ & 16.155 & 8.695 & 5.591 & 33.283 & 20.808 & 18.852 & 28.523 & 26.859 & 24.615 \\
\hline $\mathrm{V}^{*}\left[\mathrm{~mm}^{3}\right]$ & 1319.532 & 710.180 & 456.661 & 2718.602 & 1699.622 & 1539.869 & 2329.839 & 2193.841 & 2010.583 \\
\hline
\end{tabular}

For microstructure observations, all samples were first cut perpendicular to the building direction, then mounted, ground, and polished according to the standard procedures for Ti alloys' metallography [8]. The polished samples were etched using Kroll's reagent ( $2 \% \mathrm{HF}, 4 \% \mathrm{HNO}_{3}$ in distilled water). A 
Phenom table-top Scanning Electron Microscope (SEM) equipped with an EDS detector was used to evaluate the microstructure.

\section{Results and Discussion}

\subsection{Mechanical properties}

Figure 5 compares the compressive behaviour of the as-built Ti-6Al-4V lattice structures with those of the heat-treated ones. As designed, three replicas of each condition were tested to evaluate the repeatability of the results. For all conditions, a high degree of repeatability was found. Therefore, the subsequent comparisons were made by considering the average of the three measurements. As an example, Figure 5 (a) depicts the three replicas built with the geometry structure II and tested under the thermal heat treatment HT1.
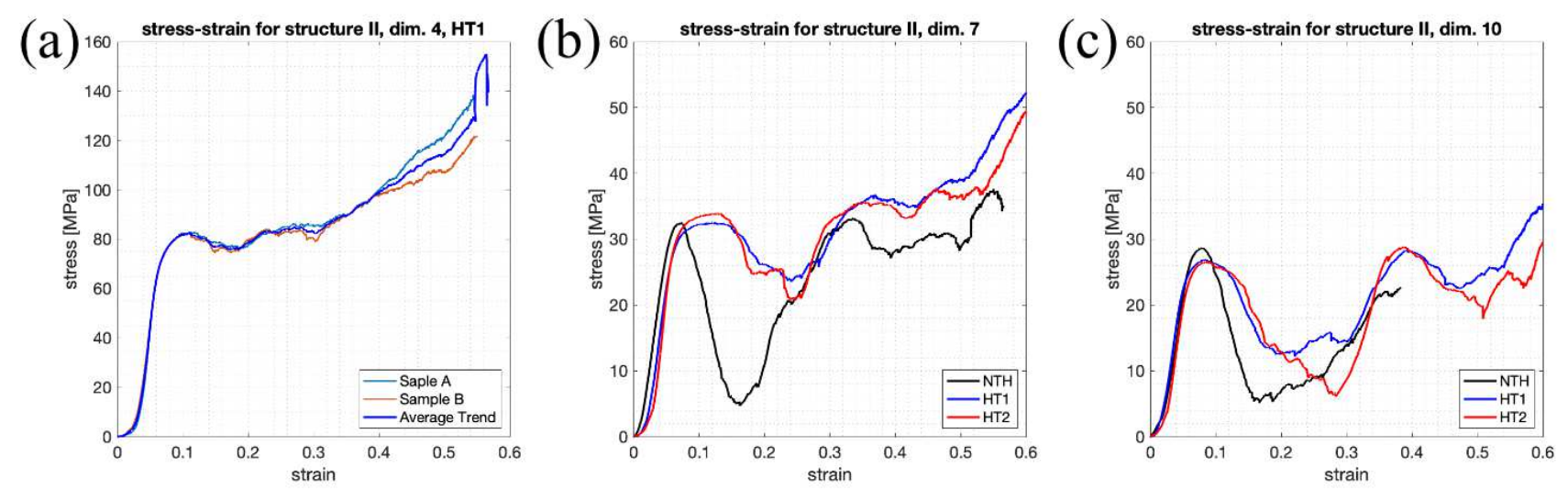

Figure 5. Compressive trends of (a) design II-4 in the HT1 condition, (b) design II-7 and (c) design II-10.

As discussed above, the compressive trend of as-built lattice structure consisted of three major parts. This behaviour was also observed in the heat-treated samples produced with different cell size combinations and types. Figure 5 (b) and 5 (c) compare the compressive stress-strain for the geometry structure II in three different states: As-built (NTH), heat-treated below (HT1) and above (HT2) the $\beta$ transus temperature. As can be seen, the compressive behaviour of the heat-treated samples was similar and had a softer trend with respect to the as-built sample. The second segment of all the curves was still characterized by a plateau region in multiple stress fluctuations can be observed, standing for the layers' collapsing. The heat-treated samples showed a less pronounced stress change in the second segment of the compressive trend. As a consequence, the lattice structure had more ductile behaviour. Contrary to the as-built samples, the heat-treated samples did not show the brittle fracture with bands at $45^{\circ}$ with respect to the horizontal plane (Figure 6 (a)). Both heat-treated samples showed a more uniform failure mode, with the progressive and homogeneous collapse of the layers (Figure 6 (b)). These findings are in very good agreement with the literature results [31, 43]. The barrelling 
effect was also observed during the conduction of the compression tests in the heat-treated samples that have no failure band formation at $45^{\circ}$ (Figure $6(\mathrm{~b})$ ).

Since all the layers collapsed on the top of each other, the last part of the compression behaviour is characterized by the elastic behaviour of the bulk material in all the three analysed thermal conditions (NTH, HT1 and HT2). Overall, since after the failure point, the stress-strain trends of HT1 and HT2 were generally higher than the NTH trend, it can be stated that lattice structures showed a ductility enhancement in the heat-treated conditions.

Table 3 lists the average values of the analysed mechanical properties for each design configuration and in each thermal condition. As can be seen, no significant changes between the as-built and the heat-treated samples can be observed in terms of Young's modulus and $U C S^{*}$ of the lattice structure. This result highlights the possibility of performing the heat treatments on the structure without losing their mechanical performances. The elongation at failure $\left(A^{*}\right)$ results showed a sharp increment in the heat-treated conditions. Owing to the preservation of compressive strength, this variation proves a much more ductile behaviour of the heat-treated structure with respect to the as-built one. As far as the absorbed energy up to failure $\left(W^{*}\right)$ is concerned, the heat treatments caused an increment of this property. As also demonstrated in previous works [32], this property is strongly affected by the variation of $U C S^{*}$ or $A^{*}$. In this case, $W^{*}$ values are influenced by the high variation of $A^{*}$. The increment of $W^{*}$ proves the high absorbed energy by the treated lattice and therefore, the ductility enhancement compared to the as-built condition.

(a)

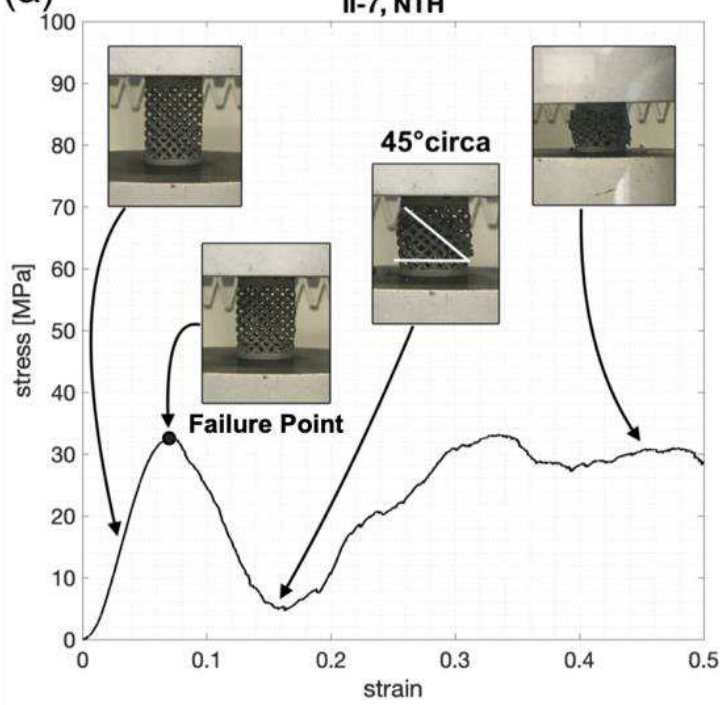

(b)

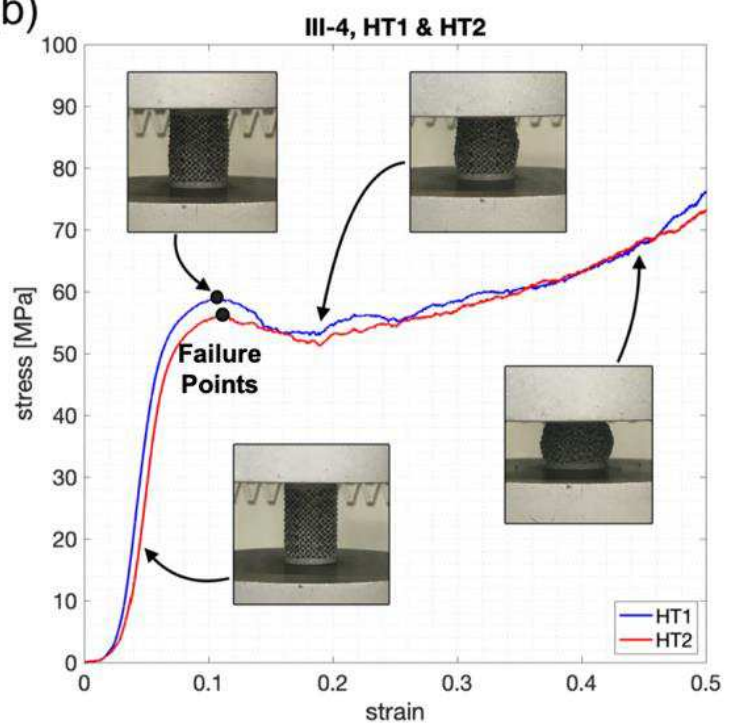

Figure 6. Compressive trends for (a) the II-7 design in the as-built condition and for (b) the III-4 design in the HT1 (blue) and HT2 (red) condition.

Table 3. Average properties of each different sample's unit cell type and size evaluated for each thermal condition 


\begin{tabular}{|c|c|c|c|c|c|c|c|c|c|c|c|c|c|}
\hline Struct. & $\begin{array}{c}\text { Cell } \\
\text { size } \\
{[\mathrm{mm}]}\end{array}$ & $\begin{array}{l}E_{\mathrm{NTH}}^{*} \\
{[\mathrm{GPa}]}\end{array}$ & $\begin{array}{l}\mathrm{E}_{\mathrm{HT} 1}^{*} \\
{[\mathrm{GPa}]}\end{array}$ & $\begin{array}{c}E_{\mathrm{HT} 2}^{*} \\
{[\mathrm{GPa}]}\end{array}$ & $\begin{array}{c}\mathrm{UCS}_{\mathrm{NTH}}^{*} \\
{[\mathrm{MPa}]}\end{array}$ & $\begin{array}{c}\mathrm{UCS}^{*}{ }_{\text {TT1 }} \\
{[\mathrm{MPa}]}\end{array}$ & $\begin{array}{c}\mathrm{UCS}_{\mathrm{HT} 2}^{*} \\
{[\mathrm{MPa}]}\end{array}$ & $\begin{array}{c}\mathrm{A}_{\mathrm{NTH}}^{*} \\
{[\%]}\end{array}$ & $\begin{array}{c}\mathrm{A}_{\mathrm{HT} 1}^{*} \\
{[\%]}\end{array}$ & $\begin{array}{c}\mathrm{A}_{\mathrm{HT} 2}^{*} \\
{[\%]}\end{array}$ & $\begin{array}{c}\mathrm{W}_{\mathrm{NTH}}^{*} \\
{[\mathrm{~kJ}]}\end{array}$ & $\begin{array}{c}\mathrm{W}^{*}{ }_{\mathrm{HT} 1} \\
{[\mathrm{~kJ}]}\end{array}$ & $\begin{array}{c}\mathrm{W}_{\mathrm{HT2}}^{*} \\
{[\mathrm{~kJ}]}\end{array}$ \\
\hline \multirow{3}{*}{ I } & 4 & 0.339 & 0.357 & 0.351 & 19.145 & 17.067 & 17.782 & 10.947 & 14.850 & 13.300 & 1.532 & 2.393 & 1.907 \\
\hline & 7 & 0.074 & 0.087 & 0.083 & 4.742 & 4.478 & 4.624 & 10.644 & 12.254 & 13.606 & 0.201 & 0.253 & 0.288 \\
\hline & 10 & 0.036 & 0.035 & 0.032 & 2.262 & 2.260 & 2.203 & 11.951 & 14.729 & 12.954 & 0.081 & 0.102 & 0.088 \\
\hline \multirow{3}{*}{ II } & 4 & 2.264 & 2.401 & 2.304 & 81.882 & 82.658 & 82.694 & 8.231 & 11.031 & 10.721 & 7.321 & 13.462 & 13.569 \\
\hline & 7 & 0.717 & 0.770 & 0.901 & 32.435 & 32.486 & 33.869 & 7.392 & 12.627 & 12.862 & 2.248 & 4.594 & 4.704 \\
\hline & 10 & 0.659 & 0.711 & 0.707 & 28.665 & 26.851 & 26.583 & 7.973 & 8.408 & 8.436 & 1.803 & 2.006 & 1.786 \\
\hline \multirow{3}{*}{ III } & 4 & 1.560 & 1.683 & 1.639 & 60.034 & 58.940 & 56.156 & 8.077 & 10.823 & 11.031 & 4.837 & 8.408 & 7.692 \\
\hline & 7 & 1.285 & 1.427 & 1.548 & 54.877 & 47.653 & 47.713 & 8.331 & 11.208 & 9.350 & 4.964 & 6.795 & 5.659 \\
\hline & 10 & 0.967 & 1.208 & 1.237 & 39.691 & 40.287 & 39.291 & 7.186 & 7.767 & 7.800 & 2.836 & 3.184 & 3.051 \\
\hline
\end{tabular}

It is well documented that the mechanical performance of lattice structures decreases mainly by increasing the unit cell size [32]. Table 3 shows the same trend for the lattice in the heat-treated conditions. As can be seen, the unit cell size increment caused a reduction in mechanical properties. The elongation at failure did not show any clear change by increasing the unit cell size (Table 3 ). It is interesting to notice that all geometries in all cell sizes showed the same trend of $E^{*}, U C S^{*}, W^{*}$. As an example, Figure 7 reports graphically the values included in Table 3 for the structure I in all sizes.

(a)

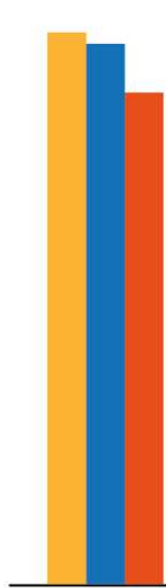

$4 \mathrm{~mm}$

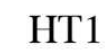

HT1

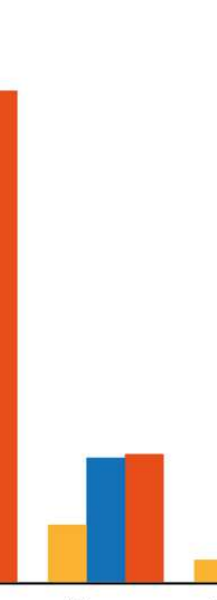

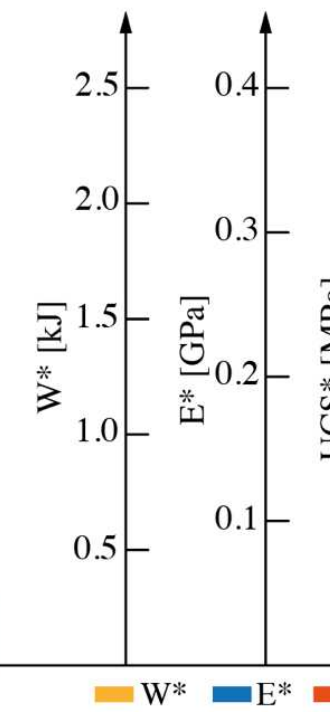

$10 \mathrm{~mm}$

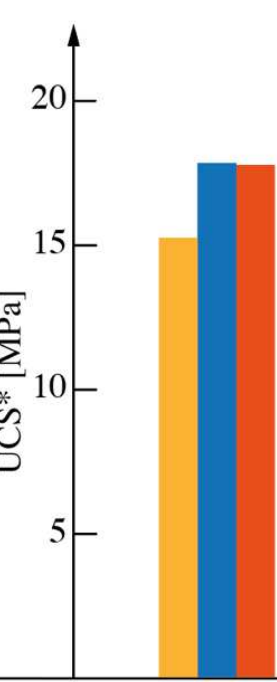

$4 \mathrm{~mm}$
HT2

(b)

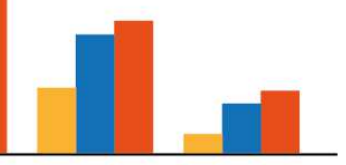

$7 \mathrm{~mm} \quad 10 \mathrm{~mm}$

Figure 7. Main mechanical properties for the specimens designed with the structure I in all the three unit cell sizes for the (a) HT1 and (b) HT2 condition.

Figure 8 depicts the effect of the unit cell type on the HT1 and HT2 samples designed with 4 mm unit cell size. As can be clearly seen, the structure I showed the worst mechanical performance while structure II was the best one. Considering the elongation at failure, the structure I showed the highest values. These trends were not consistent with the ones observed for samples designed with the $7 \mathrm{~mm}$ 
and $10 \mathrm{~mm}$ unit cell sizes. As previously observed for the as-built condition [32], this result confirms that the unit cell size has a more significant influence on the mechanical behaviour of the lattice structures.

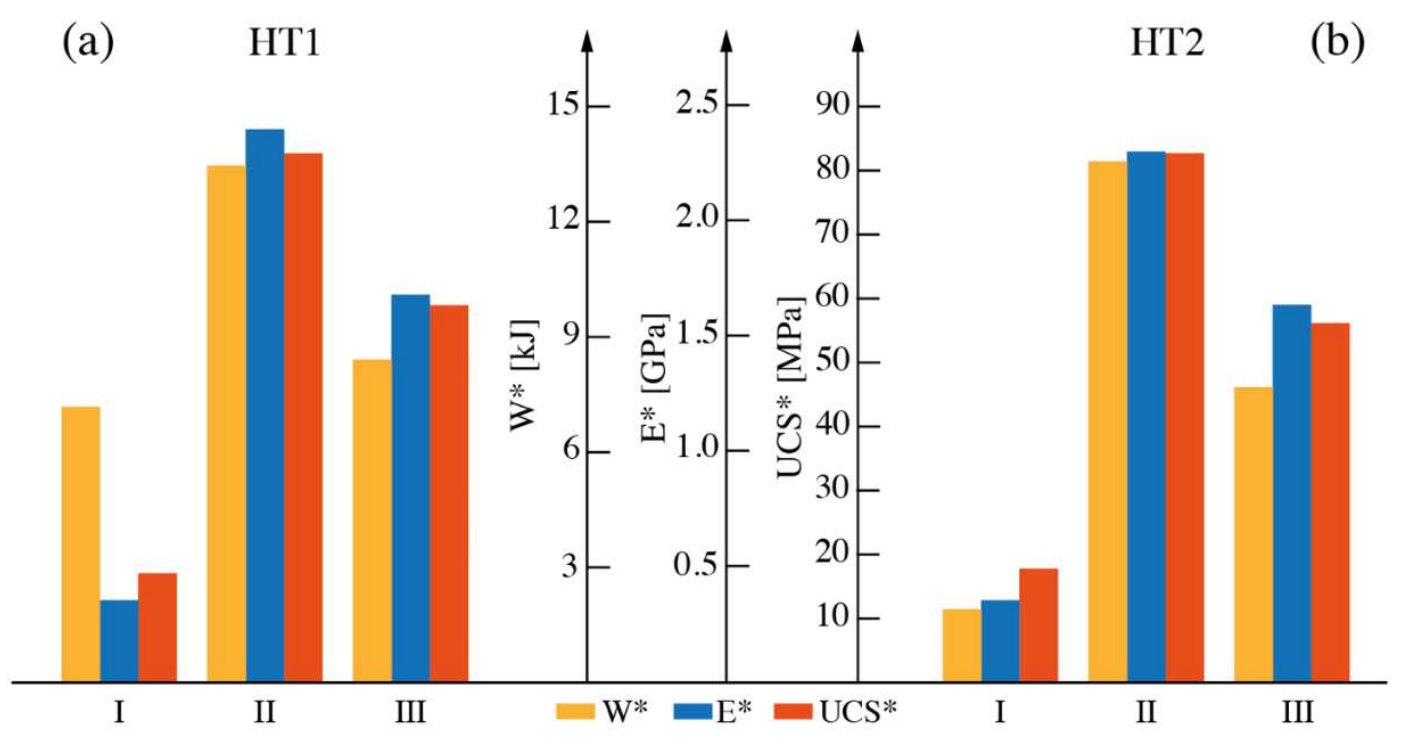

Figure 8. Main mechanical properties for the specimens designed with the $4 \mathrm{~mm}$ unit cell size in all the three structure types in the (a) HT1 and (b) HT2 condition.

The dependency between the relative density and the mechanical properties can also be derived for the heat-treated samples. Figure 9 demonstrated the values of $E^{*}, U C S^{*}$ and $W^{*}$ for all the thermal conditions and each design according to the relative density of the structure. As can be seen, the sample designed with the geometry structure I with the unit cell of dimension $10 \mathrm{~mm}$ (Structure I-10) had the lowest relative density and showed the minimum of $W^{*}, E^{*}$ and $U C S^{*}$ in each thermal condition. The structure II-4 had the highest relative density and showed the best values of the analysed mechanical properties in all the NTH, HT1 and HT2 condition. In general, it can be observed that the mechanical performances of lattice structures, for the analysed indexes, increase by increasing the relative density of the structures. 


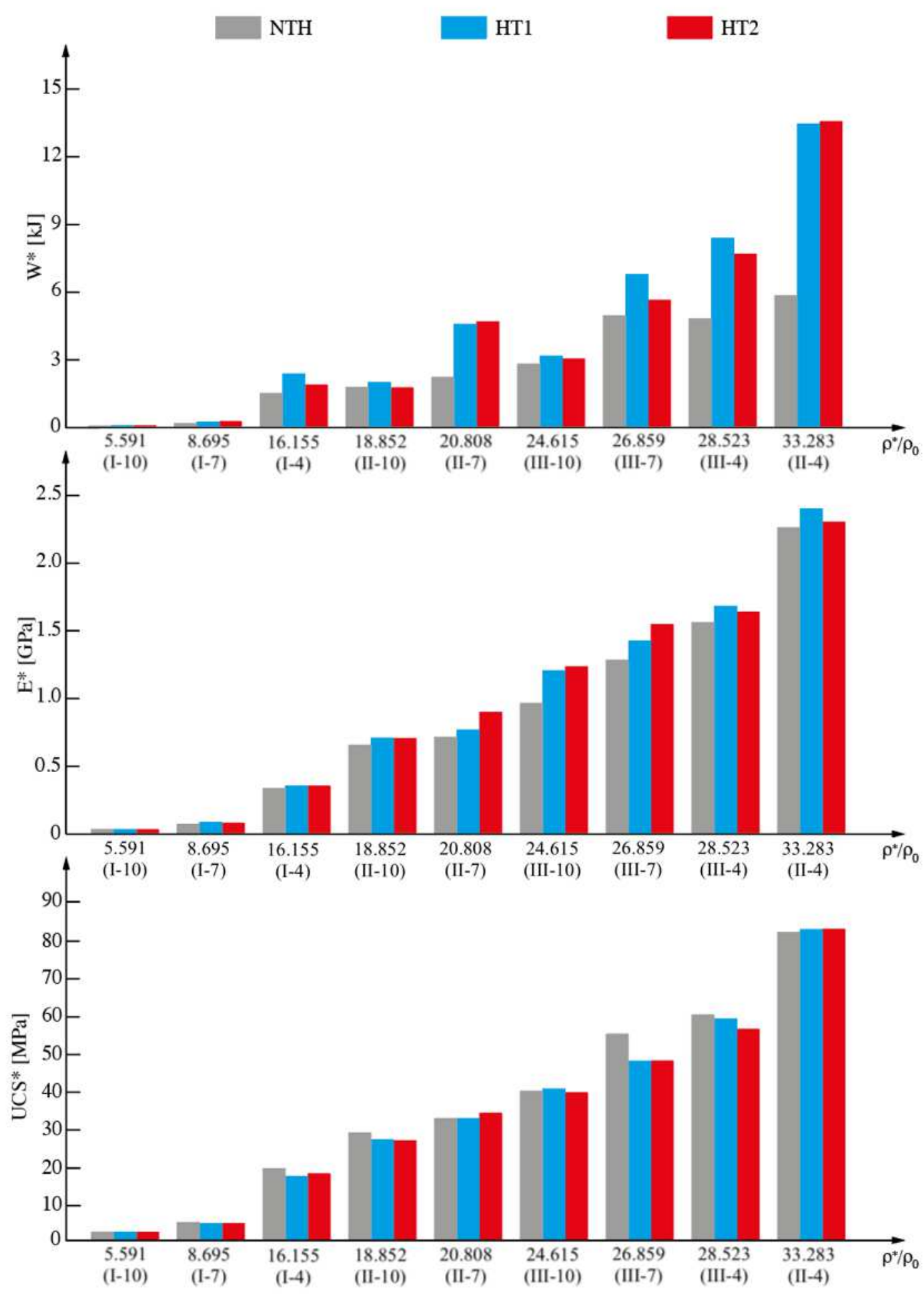

Figure 9. Variation of the mechanical properties according to the relative density of the structure in the NTH (grey), HT1 (blue) and HT2 (red) condition.

According to the Ashby and Gibson model [18], Young's modulus has a linear relationship in a bilogarithmic diagram with respect to the relative density:

$$
\frac{E^{*}}{E_{S}}=C_{1}\left(\frac{\rho^{*}}{\rho_{S}}\right)^{n}
$$


$E_{S}$ is the stiffness of the bulk material (which for the bulk Ti-6Al-4V alloy was chosen equal to 120 $\mathrm{GPa}$ [44]), $\mathrm{C} 1$ and $\mathrm{n}$ are constants equal to 12 , respectively. Figure 10 shows the experimental results for each of the analysed thermal conditions compared with the theoretical one of the Ashby and Gibson model [18] (black line). For each design, the performed heat treatment had no significant effect on Young's modulus' values. The interpolation of the experimental data highlights the trend for each of the studied thermal conditions. According to our previous work [32], the values of the constants $\mathrm{C}_{1}$ and the exponent $n$ for the samples in the as-built conditions are equal to 0.301 and 2.493, respectively. Regarding the HT1 condition, $C_{1}$ is equal to 0.280 , and $n$ is equal to 2.365 . For the HT2 condition, the $C_{1}$ and $n$ are equal to 0.219 and 2.168, respectively. The comparison between the experimental data and the theoretical one showed a constant deviation where the values calculated according to the Ashby and Gibson model [18] were always higher. The difference can be explained by the fact that the number of sharp edges and corners in a repetitive structure as in the case of the lattice structure was higher than the one present in stochastic structures as in the Ashby case Gibson analyses [18]. These geometrical features acted as stress concentration points that lower the lattice's overall stiffness with respect to stochastic one [18].

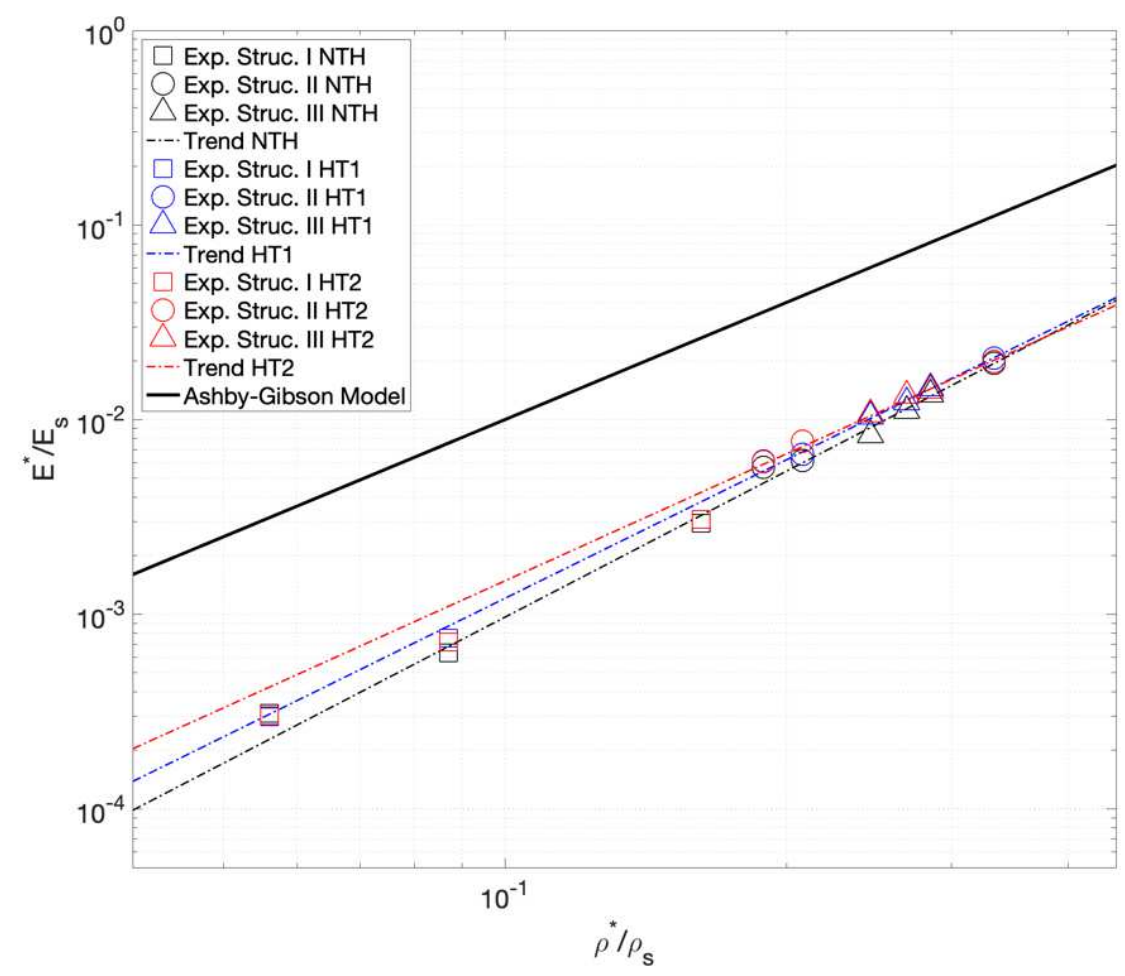

Figure 10. Bi-logarithmic diagram of the relative Young's modulus as a function of the relative density for the NTH condition (black), for the HT1 condition (blue) and for the HT2 condition (red).

Similarly, to Young's modulus, also the $U C S^{*}$ can be described by a relationship with respect to the relative density: 


$$
\frac{U C S^{*}}{U C S_{S}}=C_{5}\left(\frac{\rho^{*}}{\rho_{S}}\right)^{m}
$$

Where $U C S_{S}$ is the Ultimate Compressive Strength of the bulk material (assumed equal to $1000 \mathrm{MPa}$ ) and $C_{5}$ and $m$ are constants equal to 0.3 and 1.5 , respectively [18].

Figure 11 shows the comparison between the experimental trends and the theoretical one. According to the findings for the as-built Ti-6Al-4V lattice structures [32], $C_{5}$ and $m$ are assumed equal to 0.744 and 2.012, respectively. For the heat-treated samples, $C_{5}$ and $m$ were calculated. $C_{5}$ is equal to 0.697 and 0.806 while $m$ is 1.941 and 2.100 for the HT1 and HT2 conditions, respectively. Differently from the $E^{*}$, the experimental trends of $U C S^{*}$ were closer to the Ashby-Gibson model [18].

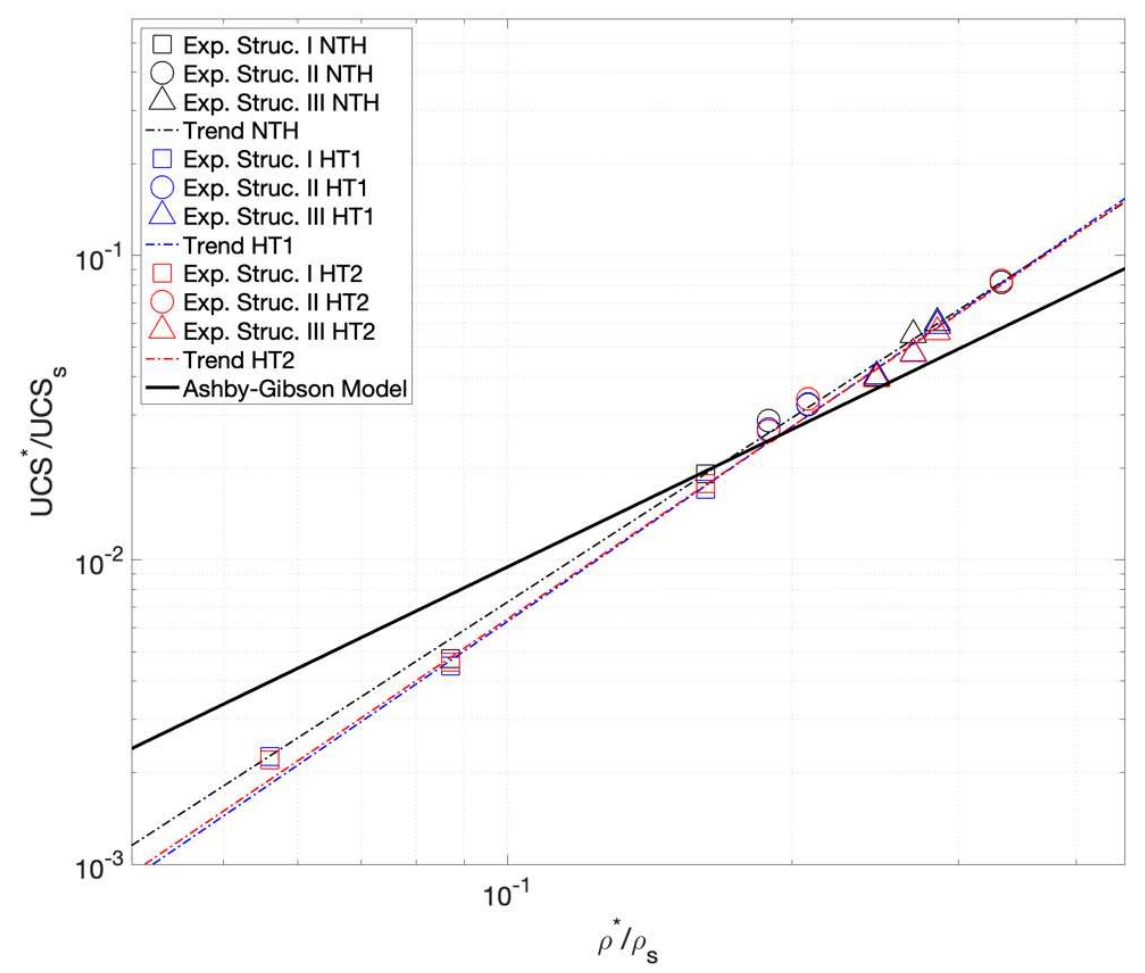

Figure 11. Bi-logarithmic diagram of the relative $\mathrm{UCS}^{*}$ as a function of the relative density for the NTH condition (black), for the HT1 state (blue) and the HT2 condition (red).

Following the findings reported for the as-built Ti-6Al-4V lattice structures [32] about the existing linear relationship in a bi-logarithmic diagram between the relative $W^{*}$ and the relative density in the as-built samples, a linear interpolation was also searched in the case of heat-treated samples. According to previous works [32], the absorbed energy up to failure can be described by the following equation:

$$
\frac{W^{*}}{W_{S}}=C\left(\frac{\rho^{*}}{\rho_{S}}\right)^{x}
$$

In Eq. 7, where $W_{S}$ represents the absorbed energy up to the failure of the bulk material, while $C$ and $x$ are constants and equal to 3.153 and 2.472, respectively, for lattice in the as-built conditions [32]. 
Regarding the HT1 and HT2 conditions, the $C$ is equal to 11.372 and 16.363 while the $x$ is 3.101 and 3.437 , respectively. The increment of the constants in the heat-treated condition compared to the asbuilt one shows the enhancement in ductility of the material after the heat treatment. Figure 12 compares the experimental trends.

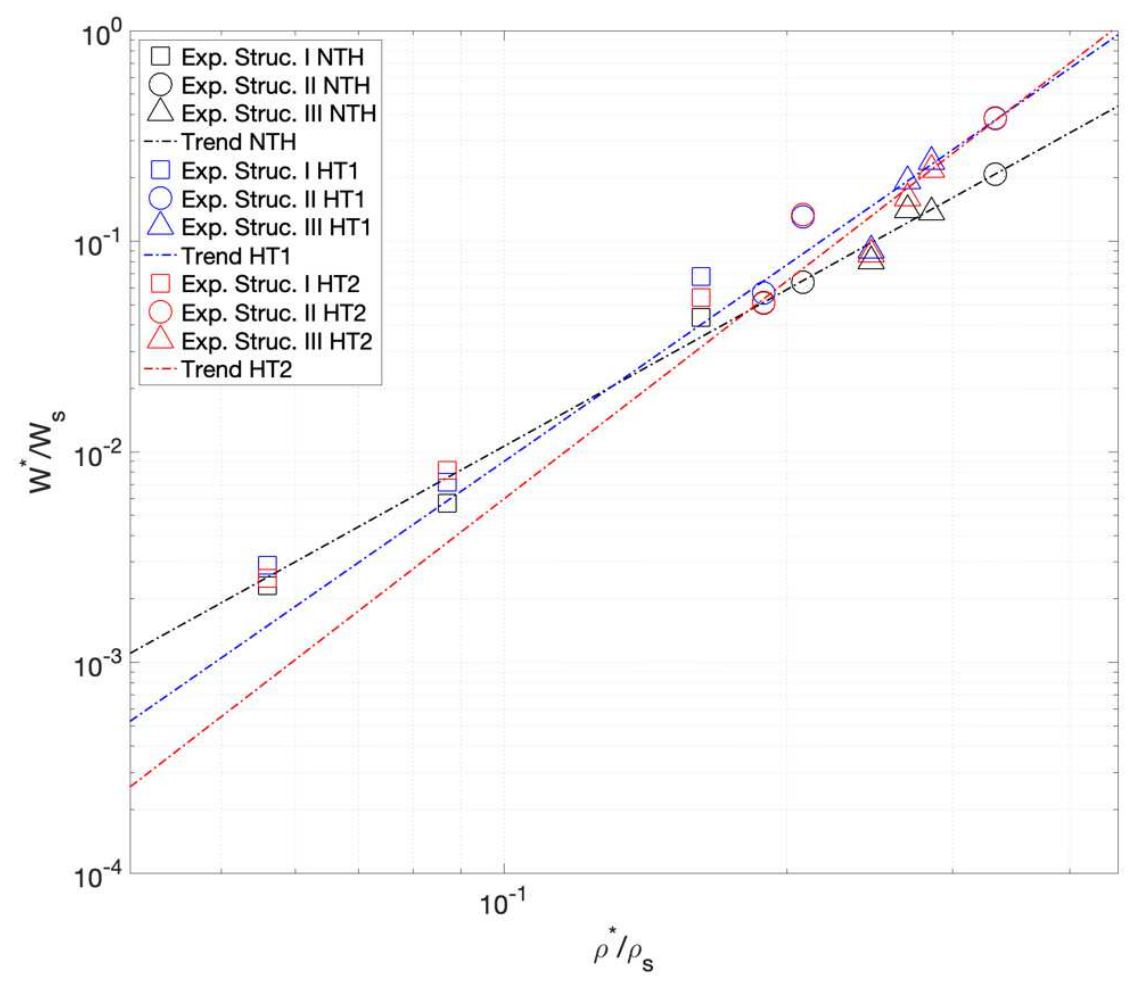

Figure 12. Bi-logarithmic diagram of the relative $\mathrm{W}^{*}$ as a function of the relative density for the NTH condition (black), for the HT1 state (blue) and the HT2 condition (red).

All in all, from a mechanical point of view, it is possible to state that lattice structures in the heattreated conditions are able to preserve stiffness and strength with the increasing of $A^{*}$. The ductility enhancement due to the increased $A^{*}$ and as a consequence of $W^{*}$ also explains the change in failure mode, which was shown in Figure 6.

\subsection{Microstructure analysis}

In general, the EBM process is able to guarantee a unique microstructure due to its rapid solidification and high temperature in the chamber. In particular, preferred crystallographic orientations and thus, specific mechanical features can be achieved. In addition, differently from other metal AM techniques, the high temperature in the building chamber is able to stop the solidification process at temperatures far higher with respect to the ambient temperature [13]. This specific feature in some unique microstructural characteristics that can hardly be achieved through the laser-based techniques. Post-manufacturing heat treatments can change the obtained microstructure, guaranteeing a vast 
variety of mechanical features. Despite this, the rapid solidification of the EBM process can also result in micro-segregation and formation of metastable phases. Previous studies [19, 26] have reported indeed the presence of hexagonally-packed acicular martensite known as the $\alpha^{\prime}$ phase. However, the typical microstructure for the as-built condition consists of acicular $\alpha$ (known as Widmastätten platelet structure) surrounded by the $\beta$ phase. This variety of microstructure achieved in the as-built condition shows the effect of the design of samples on the solidification of Ti-6Al-4V samples. Thin structures may show a more severe thermal gradient, resulting in a diffusionless transformation with the formation of $\alpha^{\prime}$ martensite. Additionally, the heat transported during the melting of the next layer on the previous one may promote the diffusion, and a solid-state transformation may lead to the dissolution of the cited metastable phase. Del Guercio et al. [32], showed that in the as-built condition, the lattice structures are characterized by the typical microstructure of EBM Ti-6Al-4V which is composed of columnar grains of the prior $\beta$ phase growing in the building direction and Widmanstätten $\alpha$ platelets. Additionally, the cell type and size play a negligible role on the microstructure of specimens. The resulting microstructure of as-built samples showed an average thickness of the $\alpha$ platelets in the range between $1 \mu \mathrm{m}$ and $2 \mu \mathrm{m}$.

Figure 13 depicts SEM images for the specimens with the geometry corresponding to the structure I and all unit cell sizes in the HT1 (a-b-c) and HT2 (d-e-f) conditions. The microstructure of heattreated samples is still composed of a combination of $\alpha$ and $\beta$ phases. Comparing the heat-treated conditions, no important microstructure changes are observed. Specifically, the width of the $\alpha$ platelets seems not to be influenced by the unit cell type. Thus, the microstructure of lattice specimens in the heat-treated conditions depends only on the parameters adopted during the thermal cycle. This result is a direct consequence of the equilibrium conditions guaranteed by the used heat treatments. Diffusion mechanisms can ensure both general grain growth and a coarsening of the $\alpha$ phase. The width of these platelets has been found to range between $3 \mu \mathrm{m}$ and $4 \mu \mathrm{m}$ for the HT1 condition and between $5 \mu \mathrm{m}$ and $8 \mu \mathrm{m}$ for the HT2. The difference between the two heat-treated conditions can be explained by the different treatment temperature of the thermal cycles. HT1 samples are heat-treated at a lower temperature in comparison with the HT2 ones. Since the solute diffusion is a direct function of the thermal condition achieved during heat treatment, higher temperatures will correspond to a higher degree of diffusion within the material. This results in a higher movement of solutes from the $\beta$ phase to the $\alpha$ phase which will consequently grow. An increment of the transversal size of the $\alpha$ lats well explains the increment of ductility previously observed. 

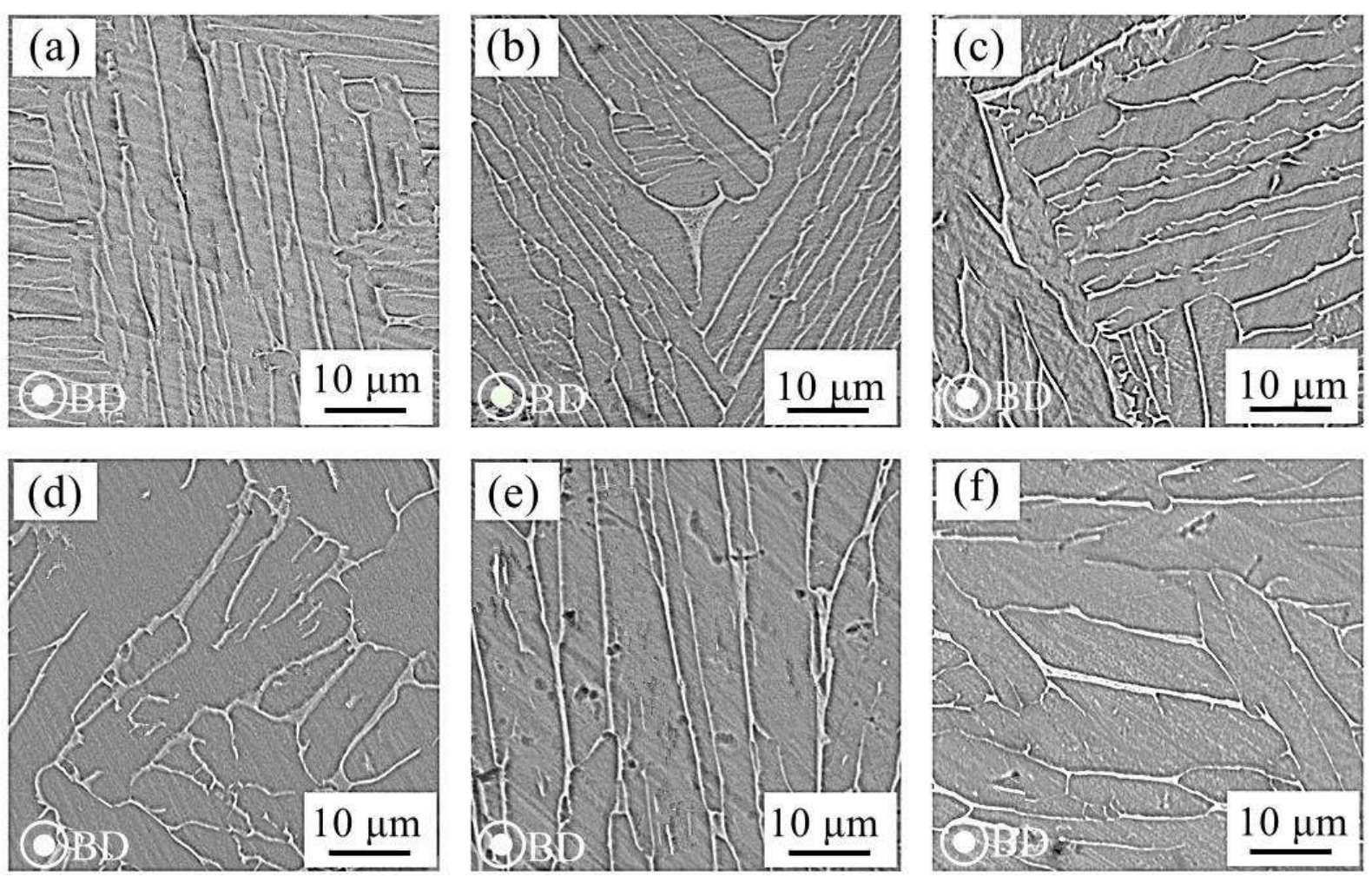

Figure 13. microstructure of (a) I-4 HT1, (b) II-4 HT1, (c) III-4 HT1, (d) I-4 HT2, (e) II-4 HT2 and (f) III-4 HT2

\section{Conclusions}

The effect of the heat treatments on the microstructure and mechanical behaviour of Ti-6Al-4V lattice structures manufactured by EBM was analysed in the present work. In particular, the effect of the unit cell size and unit cell type were investigated for the as-built and heat-treated samples. The main mechanical properties were compared with the Ashby and Gibson model. The main results can be summarized as follows:

1. A more homogeneous failure mode, typically more ductile, was found for samples in the heattreated conditions with respect to the as-built ones. In addition, the barrelling effect was observed in all the samples after the heat treatment.

2. Like the as-built samples, the heat-treated ones did not show a clear effect of the unit cell type and size on their mechanical performance. Nevertheless, the relative density of the structures was the main factor influencing their mechanical behaviour also in the HT1 and HT2 conditions.

3. The heat treatments were able to preserve the stiffness and the compressive strength of the lattice structures. In addition, an increment of both the elongation at failure and the absorbed energy was detected. These increases explain the change in failure mode observed during compression tests. 
4. The Young's modulus, UCS and W of the lattice structures in the heat-treated conditions still follow a linear trend in a bi-logarithmic diagram with respect to the relative density

5. The microstructure of the lattice structures after the heat-treatments is still composed by a mix of $\alpha$ and $\beta$ phases. Same microstructural features were observed in the same thermal condition, confirming that the temperature of the heat treatment was the main features that affect the change the microstructure of Ti-6Al-4V lattices manufactured by EBM.

6. With respect to the as-built samples, the width of the $\alpha$ platelets in the heat-treated conditions increases. This result well fitted the findings of the mechanical analysis, confirming the increment of ductility due to the HT1 and HT2 conditions with respect to the as-built one.

7. The width of these platelets has been found to range between $3 \mu \mathrm{m}$ and $4 \mu \mathrm{m}$ for the HT1 condition and between $5 \mu \mathrm{m}$ and $8 \mu \mathrm{m}$ for the HT2. The difference between the two heattreated conditions can be explained by the different treatment temperature of the thermal cycles.

It should be highlighted that in the topology optimization of some complex shape components, a mix of lattice and bulk structures is used to reduce their weight keeping their mechanical performance as high as their fully bulk ones. On the other hand, the heat treatment of bulk parts is highly recommended to improve their mechanical performance. This work clearly exhibited that the recommended heat treatments for the bulk materials can also modify the microstructure of the lattice part and as a consequence, their mechanical properties.

\section{Declarations}

Funding: No funding was received for conducting this study.

Conflicts of interest/Competing interests: The authors declare that they have no known competing financial interests or personal relationships that could have appeared to influence the work reported in this paper.

Availability of data and material: The datasets generated during and/or analysed during the current study are available from the corresponding author on reasonable request.

Code availability: Not applicable.

Ethics approval: This chapter does not contain any studies with human participants or animals performed by any of the authors. Authors acknowledge the work is original and all the relevant text from the literature has been properly cited. 
Authors' contributions: Manuela Galati and Abdollah Saboori conceived and designed the experiment. Giuseppe Del Guercio performed the characterizations and collected the data. All the authors analyzed and interpreted the data. Giuseppe Del Guercio wrote and revised the manuscript. Manuela Galati and Abdollah Saboori revised the manuscript and approved the final version to be submitted.

Consent to participate: Authors agree to the authorship order.

Consent for publication: All authors have read and agreed to the published version of the manuscript.

\section{References}

1. ASTM (2013) F2792-12a - Standard Terminology for Additive Manufacturing Technologies. Rapid Manuf Assoc 10-12. https://doi.org/10.1520/F2792-12A.2

2. Saboori A, Gallo D, Biamino S, et al (2017) An Overview of Additive Manufacturing of Titanium Components by Directed Energy Deposition: Microstructure and Mechanical Properties. Appl Sci. https://doi.org/10.3390/app7090883

3. Saboori A, Piscopo G, Lai M, et al (2020) An investigation on the effect of deposition pattern on the microstructure, mechanical properties and residual stress of 316L produced by Directed $\begin{array}{lllll}\text { Energy Deposition. } & \text { Mater Sci } & \text { Eng } & \text { A }\end{array}$ https://doi.org/https://doi.org/10.1016/j.msea.2020.139179

4. Saboori A, Tusacciu S, Busatto M, et al (2018) Production of Single Tracks of Ti-6Al-4V by Directed Energy Deposition to Determine the Layer Thickness for Multilayer Deposition. J Vis Exp 2018:e56966. https://doi.org/doi:10.3791/56966

5. Gibson I, Rosen DW, Stucker B Additive manufacturing technologies. Springer

6. Saboori A, Aversa A, Marchese G, et al (2019) Application of Directed Energy DepositionBased Additive Manufacturing in Repair. Appl Sci 9:. https://doi.org/10.3390/app9163316

7. Del Guercio G, Galati M, Saboori A, et al (2020) Microstructure and Mechanical Performance of Ti-6Al-4V Lattice Structures Manufactured via Electron Beam Melting (EBM): A Review. Acta Metall Sin (English Lett 33:183-203. https://doi.org/10.1007/s40195-020-00998-1

8. Saboori A, Abdi A, Fatemi SA, et al (2020) Hot deformation behavior and flow stress modeling of Ti-6Al-4V alloy produced via electron beam melting additive manufacturing technology in $\begin{array}{llllll}\text { single } \quad \beta \text {-phase } & \text { field. } & \text { Mater } & \text { Sci } & \text { Eng }\end{array}$ https://doi.org/https://doi.org/10.1016/j.msea.2020.139822 
9. Saboori A, Biamino S, Tusacciu S, et al (2017) Characterization of single track formation from Ti-6AL-4V alloy at different process parameters by Direct Energy Deposition. In: Euro PM2017 Congress \& Exhebition. pp 1-5

10. Calignano F, Galati M, Iuliano L, Minetola P (2019) Design of Additively Manufactured Structures for Biomedical Applications: A Review of the Additive Manufacturing Processes Applied to the Biomedical Sector. J Healthc Eng 2019:〈xocs:firstpage xmlns:xocs=""/>. https://doi.org/10.1155/2019/9748212

11. Galati M, Snis A, Iuliano L (2018) Experimental validation of a numerical thermal model of the EBM process for Ti6Al4V. Comput Math with Appl

12. Polmear I, StJohn D, Nie J-F, Qian M (2017) Light alloys: metallurgy of the light metals. Butterworth-Heinemann

13. Galarraga H, Warren RJ, Lados DA, et al (2017) Effects of heat treatments on microstructure and properties of Ti-6Al-4V ELI alloy fabricated by electron beam melting (EBM). Mater Sci Eng A 685:417-428. https://doi.org/10.1016/J.MSEA.2017.01.019

14. Galati M, Minetola P, Rizza G (2019) Surface Roughness Characterisation and Analysis of the Electron Beam Melting (EBM) Process. Materials (Basel) 12:2211. https://doi.org/10.3390/ma12132211

15. He W, Jia W, Liu H, et al (2011) Research on preheating of titanium alloy powder in electron beam melting technology. Xiyou Jinshu Cailiao Yu Gongcheng/Rare Met Mater Eng 40:20722075

16. Fleck NA, Deshpande VS, Ashby MF (2010) Micro-architectured materials: Past, present and future. Proc R Soc A Math Phys Eng Sci 466:2495-2516. https://doi.org/10.1098/rspa.2010.0215

17. Evans AG, Hutchinson JW, Ashby MF (1998) Multifunctionality of cellular metal systems. Prog Mater Sci 43:171-221

18. Gibson LJ, Ashby MF (1999) Cellular solids: structure and properties. Cambridge university press

19. E. ML, M. GS, F. M, et al (2010) Next-generation biomedical implants using additive manufacturing of complex, cellular and functional mesh arrays. Philos Trans R Soc A Math Phys Eng Sci 368:1999-2032. https://doi.org/10.1098/rsta.2010.0010

20. Niinomi M (2002) Recent metallic materials for biomedical applications. Metall Mater Trans A 33:477

21. Park J-W, Kim H-K, Kim Y-J, et al (2010) Osteoblast response and osseointegration of a Ti- 
6Al-4V alloy implant incorporating strontium. Acta Biomater 6:2843-2851. https://doi.org/https://doi.org/10.1016/j.actbio.2010.01.017

22. Ashby MF (2006) The properties of foams and lattices. Philos Trans R Soc A Math Phys Eng Sci 364:15-30. https://doi.org/10.1098/rsta.2005.1678

23. Maxwell JC (1864) L. on the calculation of the equilibrium and stiffness of frames. London, Edinburgh, Dublin Philos Mag J Sci 27:294-299

24. Vladimir Popov, Alexander Katz-Demyanetz, Andrey Garkun, Gary Muller, Evgeny Strokin HR, Popov V, Katz-Demyanetz A, et al (2018) Effect of Hot Isostatic Pressure treatment on the Electron-Beam Melted Ti-6Al-4V specimens. Procedia Manuf. https://doi.org/10.1016/j.promfg.2018.02.102

25. De Formanoir C, Michotte S, Rigo O, et al (2016) Electron beam melted Ti-6Al-4V: Microstructure, texture and mechanical behavior of the as-built and heat-treated material. Mater Sci Eng A 652:105-119

26. de Formanoir C, Suard M, Dendievel R, et al (2016) Improving the mechanical efficiency of electron beam melted titanium lattice structures by chemical etching. Addit Manuf 11:71-76

27. Zhai Y, Galarraga H, Lados DA (2015) Microstructure Evolution, Tensile Properties, and Fatigue Damage Mechanisms in Ti-6Al-4V Alloys Fabricated by Two Additive Manufacturing Techniques. Procedia Eng 114:658-666. https://doi.org/10.1016/J.PROENG.2015.08.007

28. Cunningham R, Nicolas A, Madsen J, et al (2017) Analyzing the effects of powder and postprocessing on porosity and properties of electron beam melted Ti-6Al-4V. Mater Res Lett 5:516-525. https://doi.org/10.1080/21663831.2017.1340911

29. Chan KS, Koike M, Mason RL, Okabe T (2013) Fatigue life of titanium alloys fabricated by additive layer manufacturing techniques for dental implants. Metall Mater Trans A 44:10101022

30. Li SJ, Murr LE, Cheng XY, et al (2012) Compression fatigue behavior of Ti-6Al-4V mesh arrays fabricated by electron beam melting. Acta Mater 60:793-802

31. Cheng XY, Li SJ, Murr LE, et al (2012) Compression deformation behavior of Ti-6Al-4V alloy with cellular structures fabricated by electron beam melting. J Mech Behav Biomed Mater 16:153-162. https://doi.org/https://doi.org/10.1016/j.jmbbm.2012.10.005

32. Del Guercio G, Galati M, Saboori A (2021) Innovative Approach to Evaluate the Mechanical Performance of Ti-6Al-4V Lattice Structures Produced by Electron Beam Melting Process. Met Mater Int 27:55-67. https://doi.org/10.1007/s12540-020-00745-2

33. Parthasarathy J, Starly B, Raman S, Christensen A (2010) Mechanical evaluation of porous 
titanium (Ti6Al4V) structures with electron beam melting (EBM). J Mech Behav Biomed Mater 3:249-259

34. Cansizoglu O, Harrysson O, Cormier D, et al (2008) Properties of Ti-6Al-4V non-stochastic lattice structures fabricated via electron beam melting. Mater Sci Eng A 492:468-474

35. Xiao L, Song W, Wang C, et al (2017) Mechanical properties of open-cell rhombic dodecahedron titanium alloy lattice structure manufactured using electron beam melting under dynamic loading. Int J Impact Eng 100:75-89

36. Suard M, Lhuissier P, Dendievel R, et al (2014) Towards stiffness prediction of cellular structures made by electron beam melting (EBM). Powder Metall 57:190-195

37. Jamshidinia M, Wang L, Tong W, Kovacevic R (2014) The bio-compatible dental implant designed by using non-stochastic porosity produced by Electron Beam Melting®(EBM). J Mater Process Technol 214:1728-1739

38. Horn TJ, Harrysson OLA, Marcellin-Little DJ, et al (2014) Flexural properties of Ti6A14V rhombic dodecahedron open cellular structures fabricated with electron beam melting. Addit Manuf 1:2-11

39. Tammas-Williams S, Withers PJ, Todd I, Prangnell PB (2016) The effectiveness of hot isostatic pressing for closing porosity in titanium parts manufactured by selective electron beam melting. Metall Mater Trans A 47:1939-1946

40. Tammas-Williams S, Withers PJ, Todd I, Prangnell PB (2016) Porosity regrowth during heat treatment of hot isostatically pressed additively manufactured titanium components. Scr Mater $122: 72-76$

41. ASTM (2019) Standard Specification for Additive Manufacturing Titanium-6 Aluminum-4 Vanadium with Powder Bed Fusion 1. i:1-9. https://doi.org/10.1520/F2924-14.2

42. Epasto G, Palomba G, Andrea DD, et al (2019) Materials Science \& Engineering A Ti-6Al4V ELI microlattice structures manufactured by electron beam melting : E ff ect of unit cell dimensions and morphology on mechanical behaviour. Mater Sci Eng A 753:31-41. https://doi.org/10.1016/j.msea.2019.03.014

43. Xiao L, Song W, Wang C, et al (2015) Mechanical behavior of open-cell rhombic dodecahedron Ti-6Al-4V lattice structure. Mater Sci Eng A 640:375-384

44. ArcamEBM (2016) Ti6Al4V Titanium Alloy 


\section{Figures}

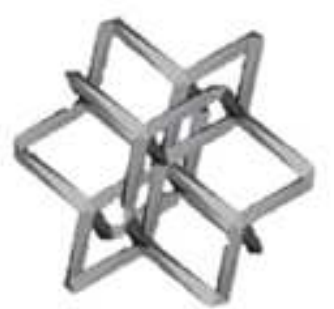

(a)

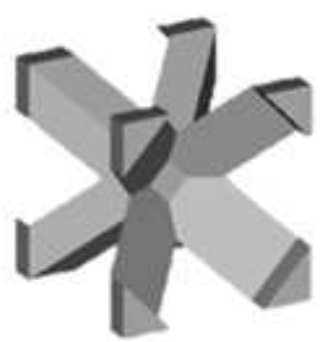

(b)

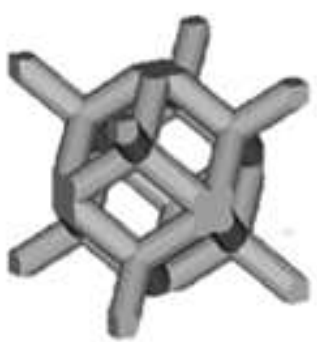

(c)

\section{Figure 1}

Unit cells used in the present work; (a) Structure I: dode thin, (b) Structure II: G-Structure 3, (c) Structure III: Rombi Dodecahedron.

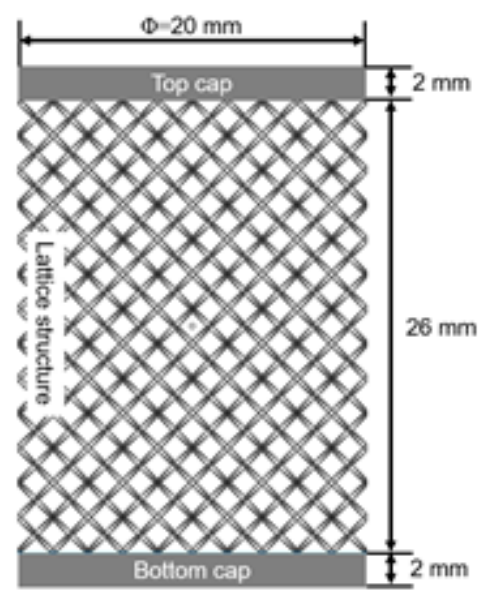

\section{Figure 2}

The general design of each specimen for the compression test. 


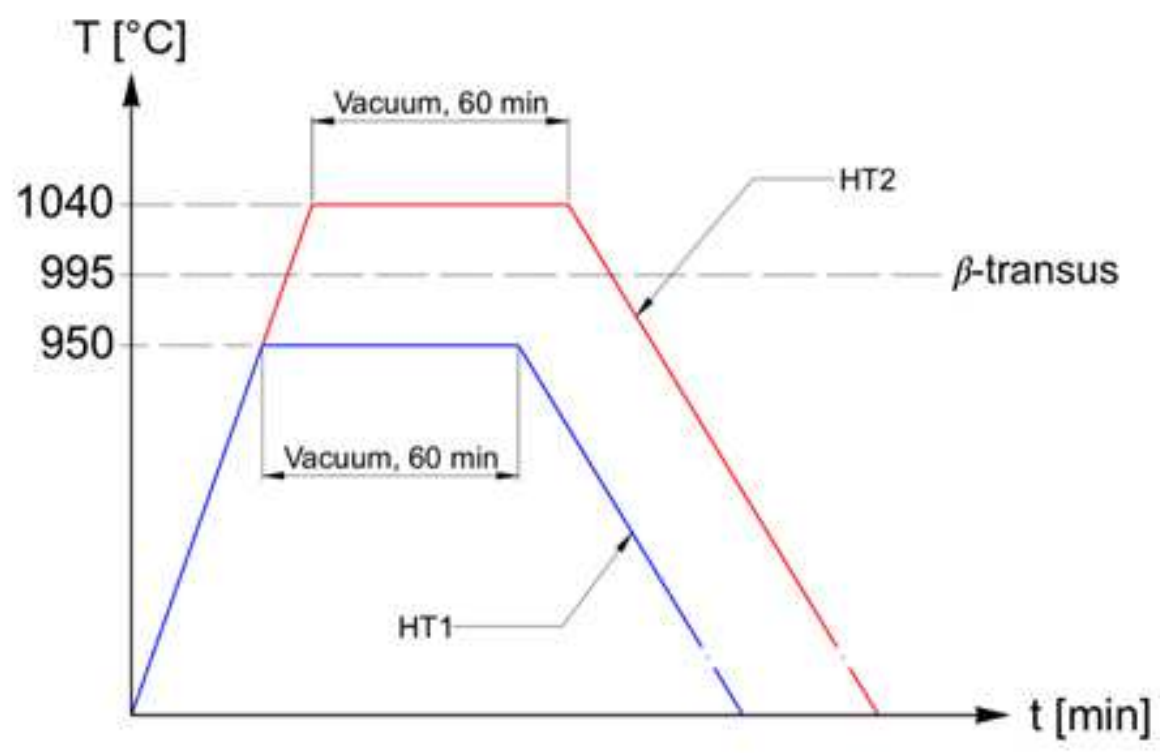

Figure 3

temperature-time curves for the designed thermal cycles.

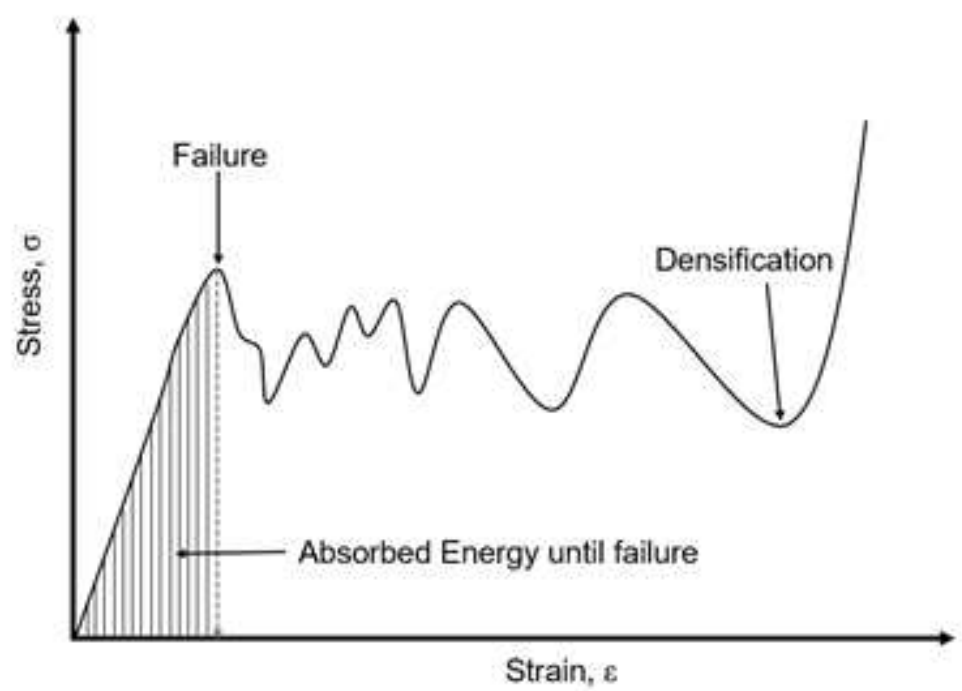

Figure 4

Qualitative stress/strain compressive trend of a generic lattice structure. 

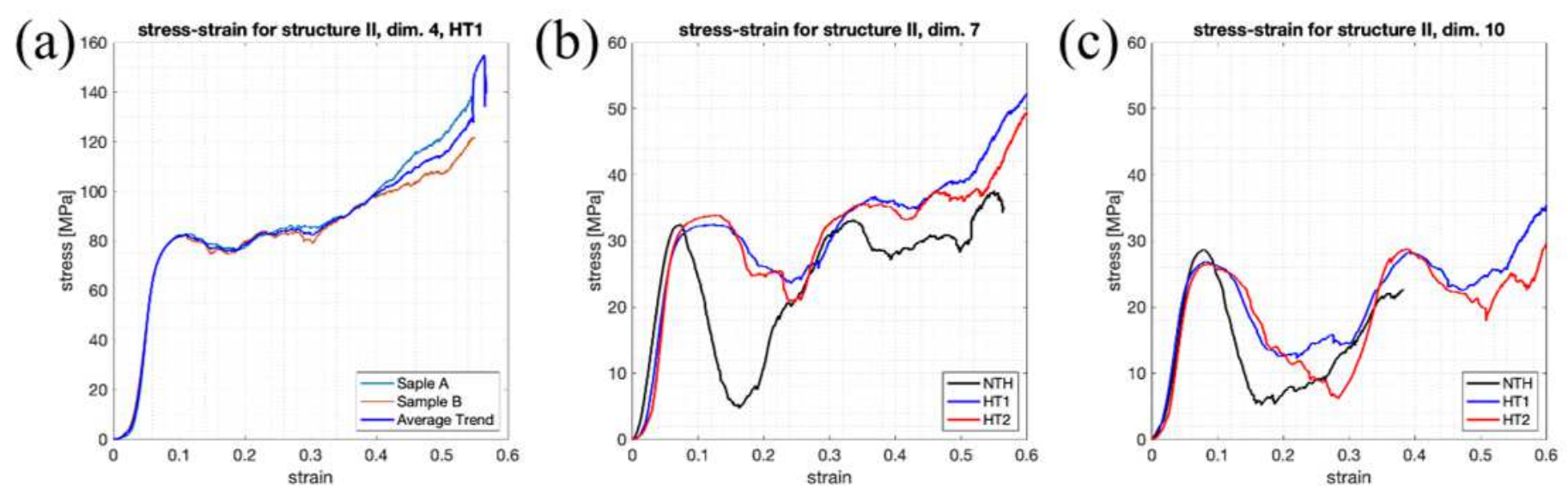

\section{Figure 5}

Compressive trends of (a) design II-4 in the HT1 condition, (b) design II-7 and (c) design II-10.

(a)

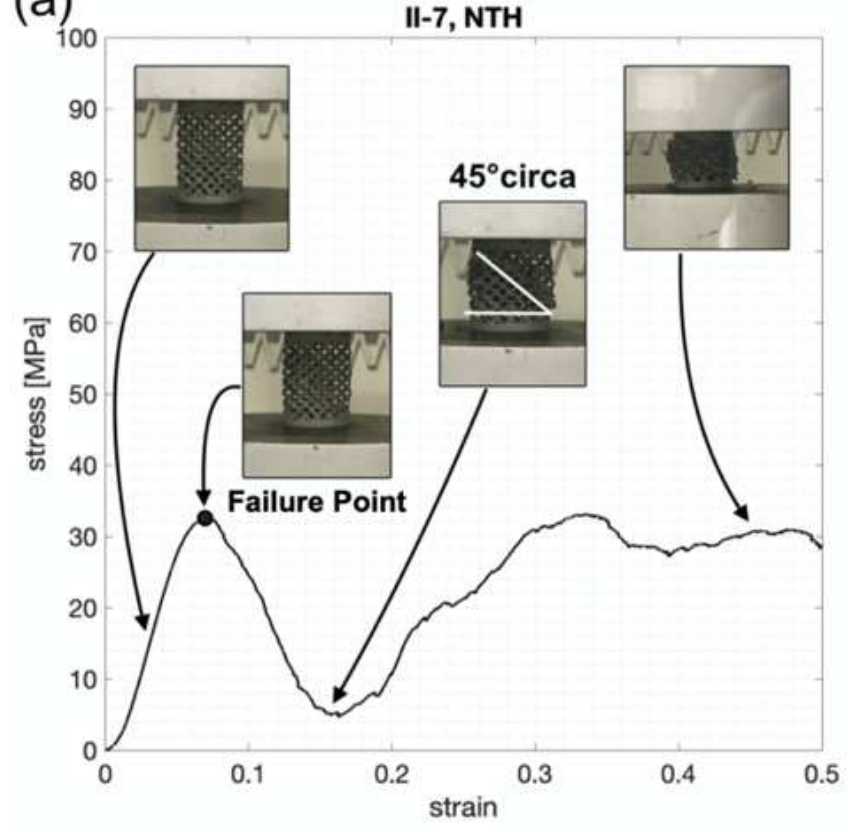

(b)

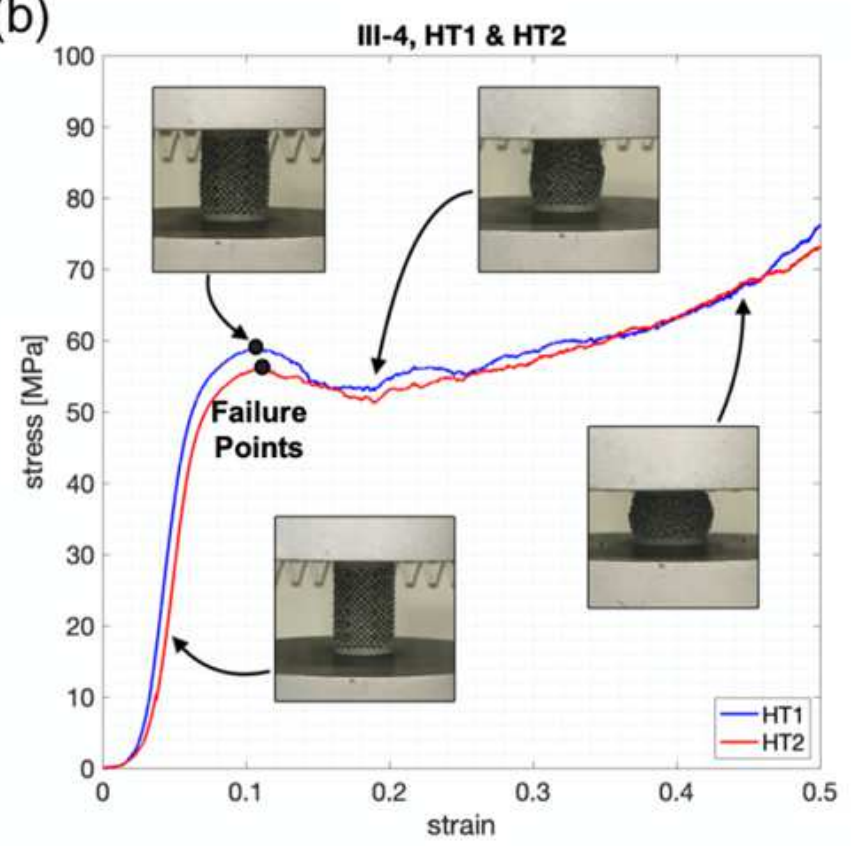

\section{Figure 6}

Compressive trends for (a) the II-7 design in the as-built condition and for (b) the III-4 design in the HT1 (blue) and HT2 (red) condition. 


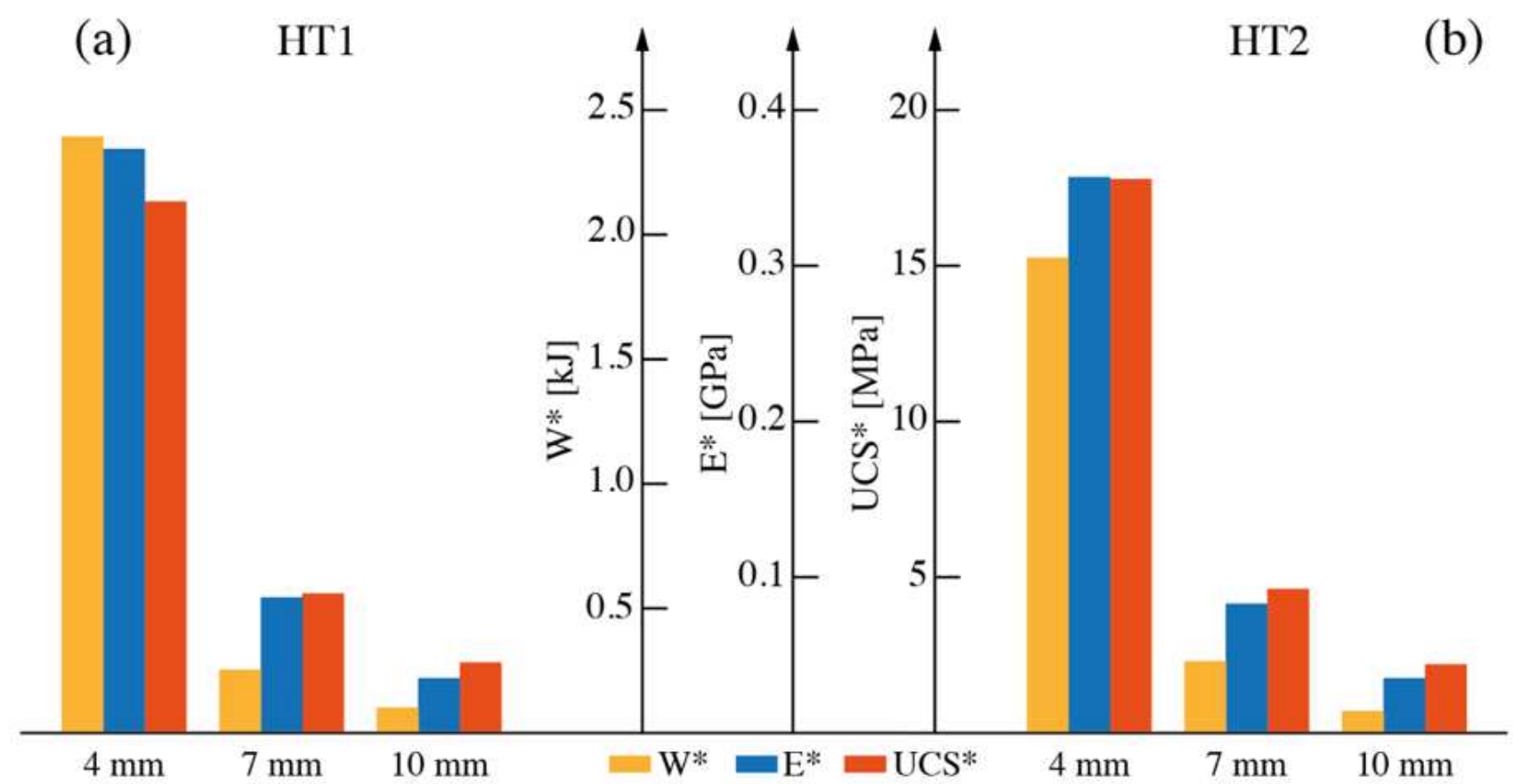

Figure 7

Main mechanical properties for the specimens designed with the structure I in all the three unit cell sizes for the (a) HT1 and (b) HT2 condition.

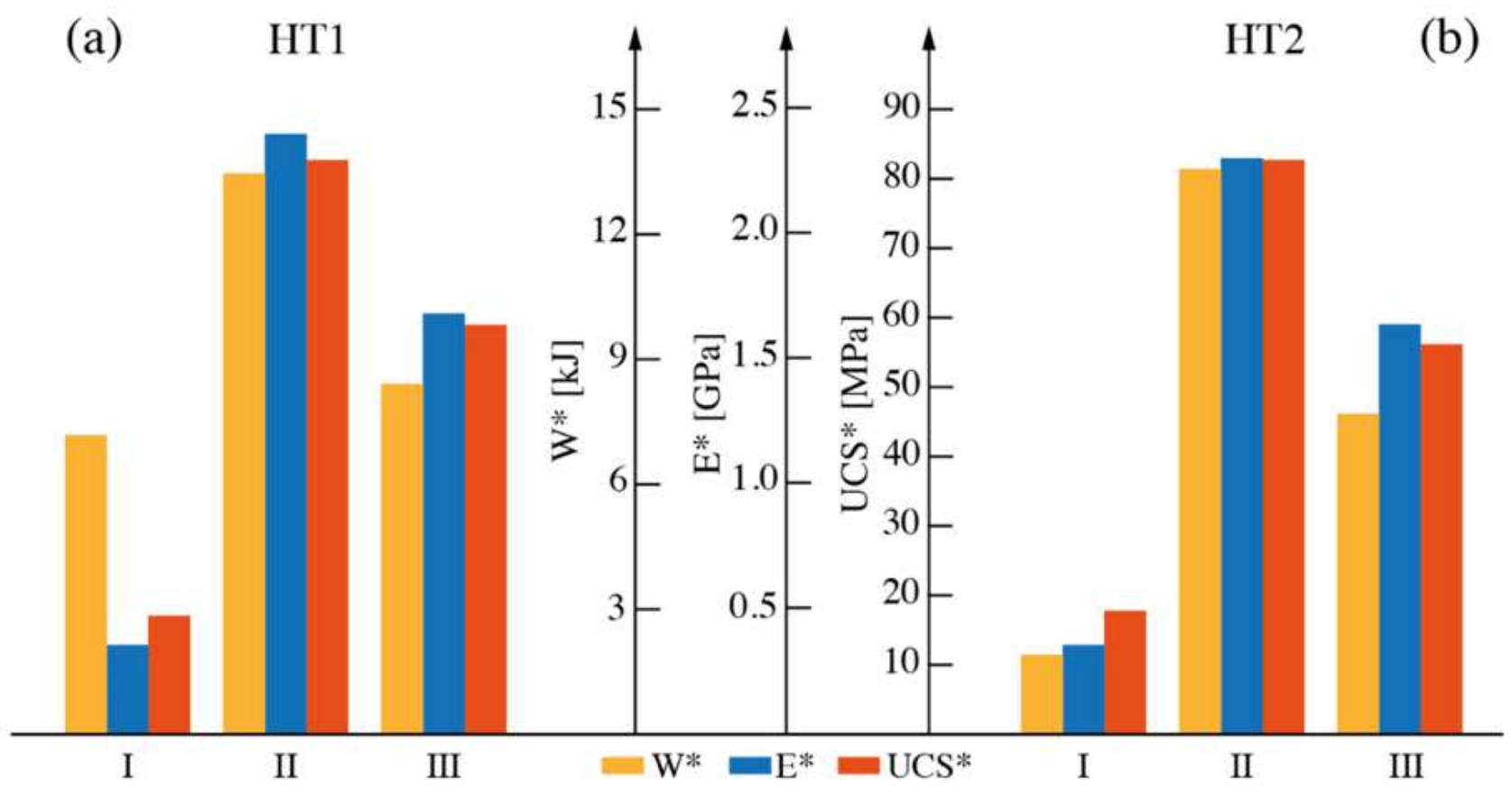

Figure 8 
Main mechanical properties for the specimens designed with the $4 \mathrm{~mm}$ unit cell size in all the three structure types in the (a) HT1 and (b) HT2 condition.

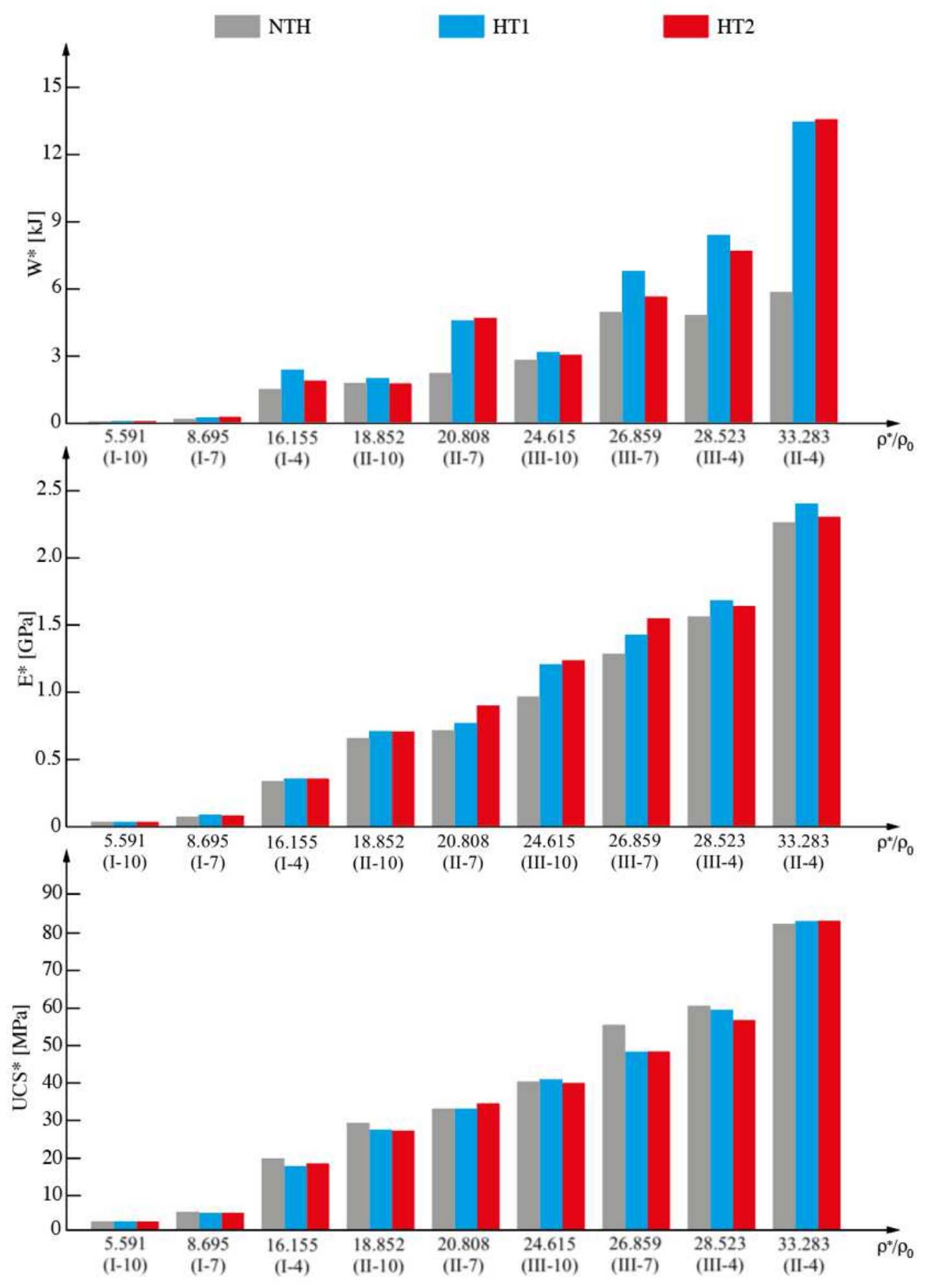

Figure 9

Variation of the mechanical properties according to the relative density of the structure in the NTH (grey), HT1 (blue) and HT2 (red) condition. 


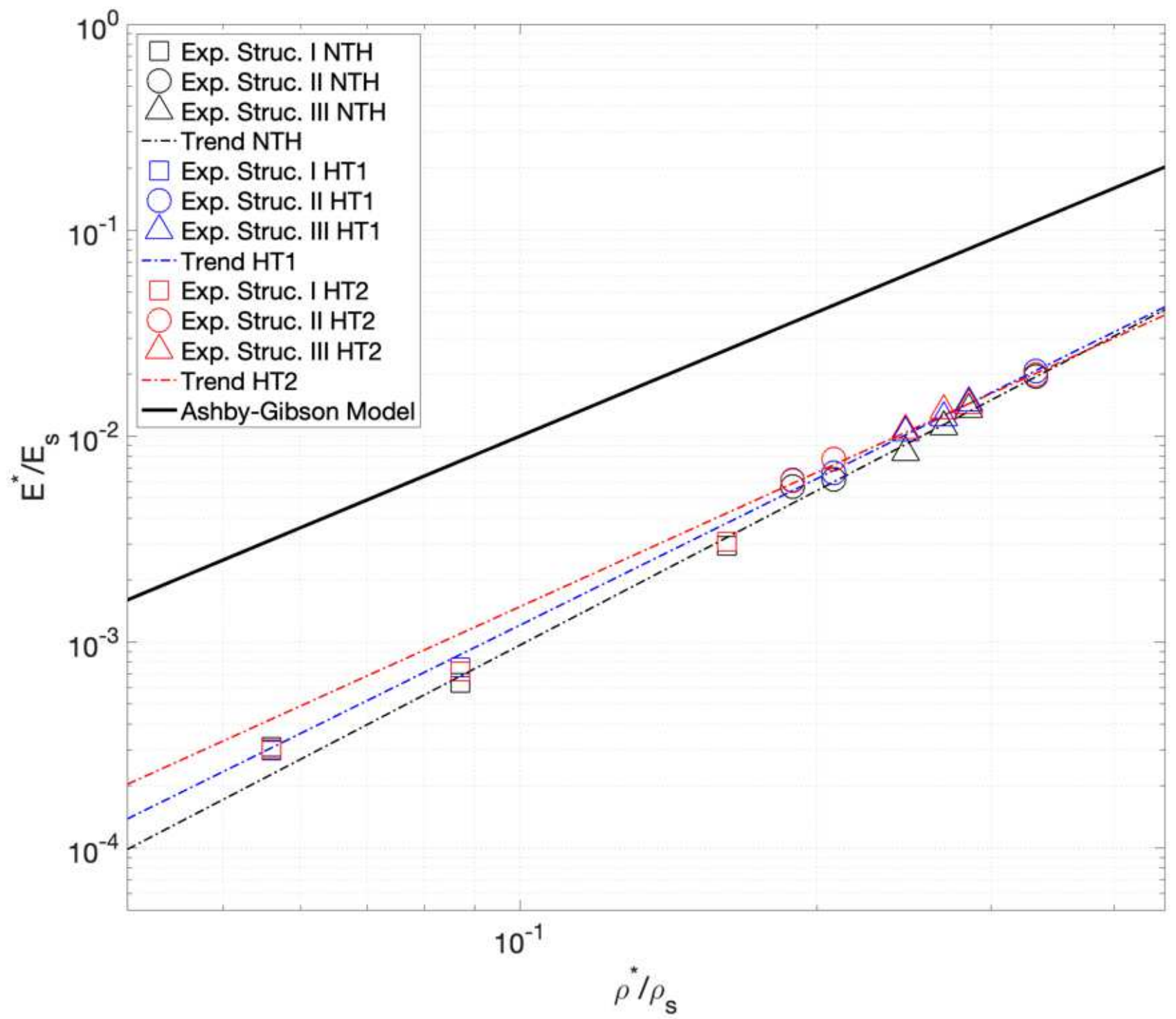

Figure 10

Bi-logarithmic diagram of the relative Young's modulus as a function of the relative density for the NTH condition (black), for the HT1 condition (blue) and for the HT2 condition (red). 


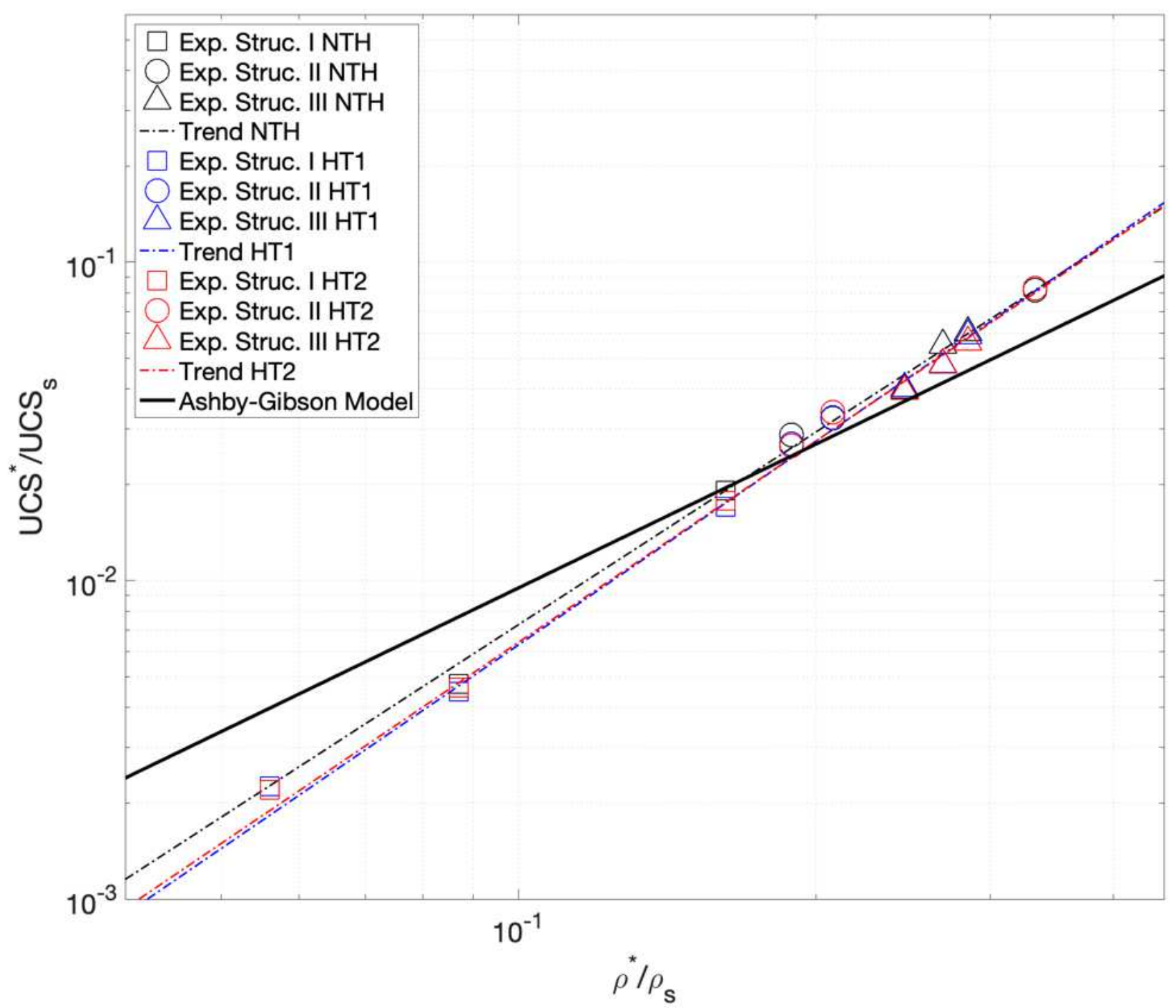

Figure 11

Bi-logarithmic diagram of the relative UCS* as a function of the relative density for the NTH condition (black), for the HT1 state (blue) and the HT2 condition (red). 


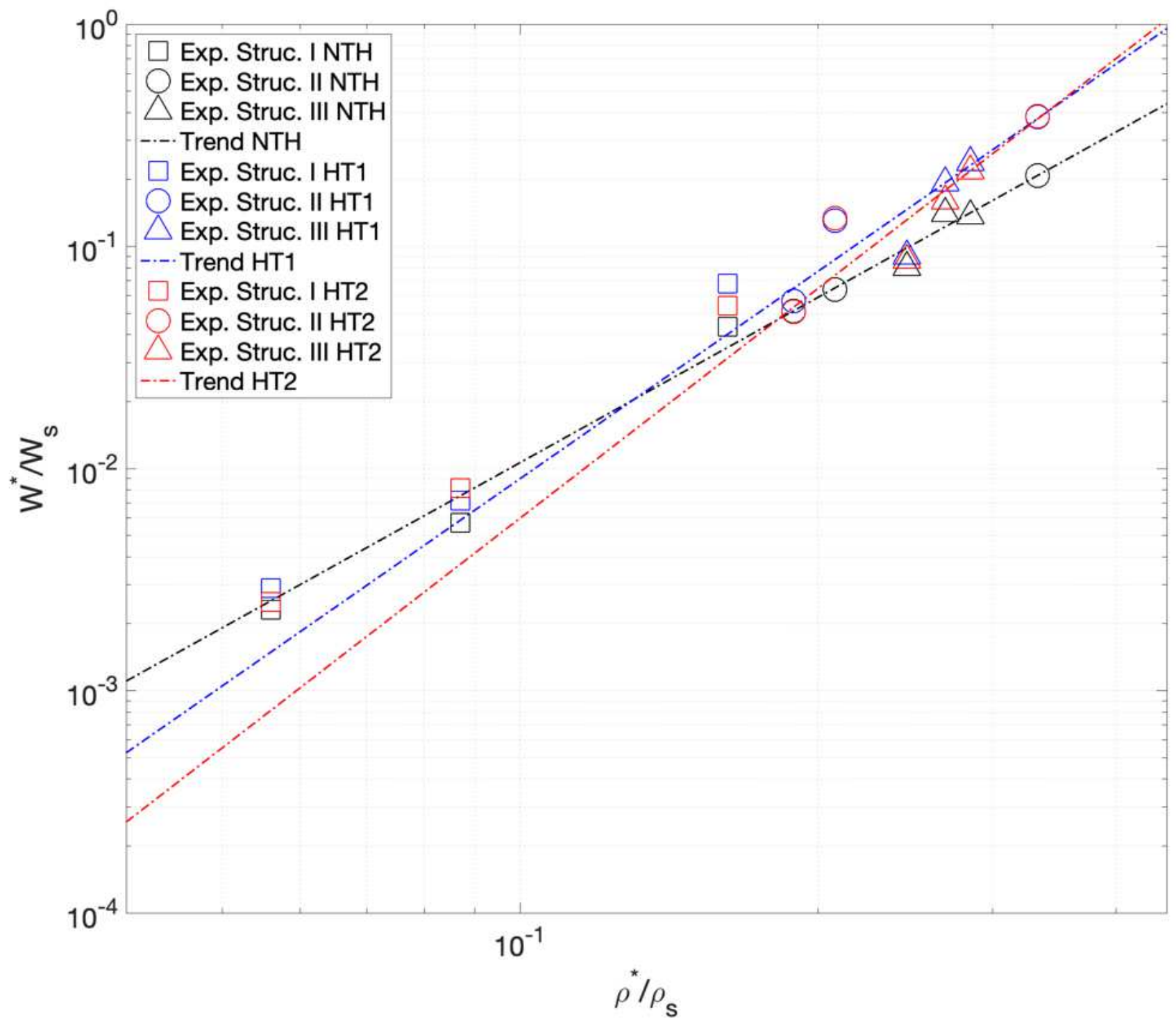

Figure 12

Bi-logarithmic diagram of the relative $\mathrm{W}^{*}$ as a function of the relative density for the NTH condition (black), for the HT1 state (blue) and the HT2 condition (red). 

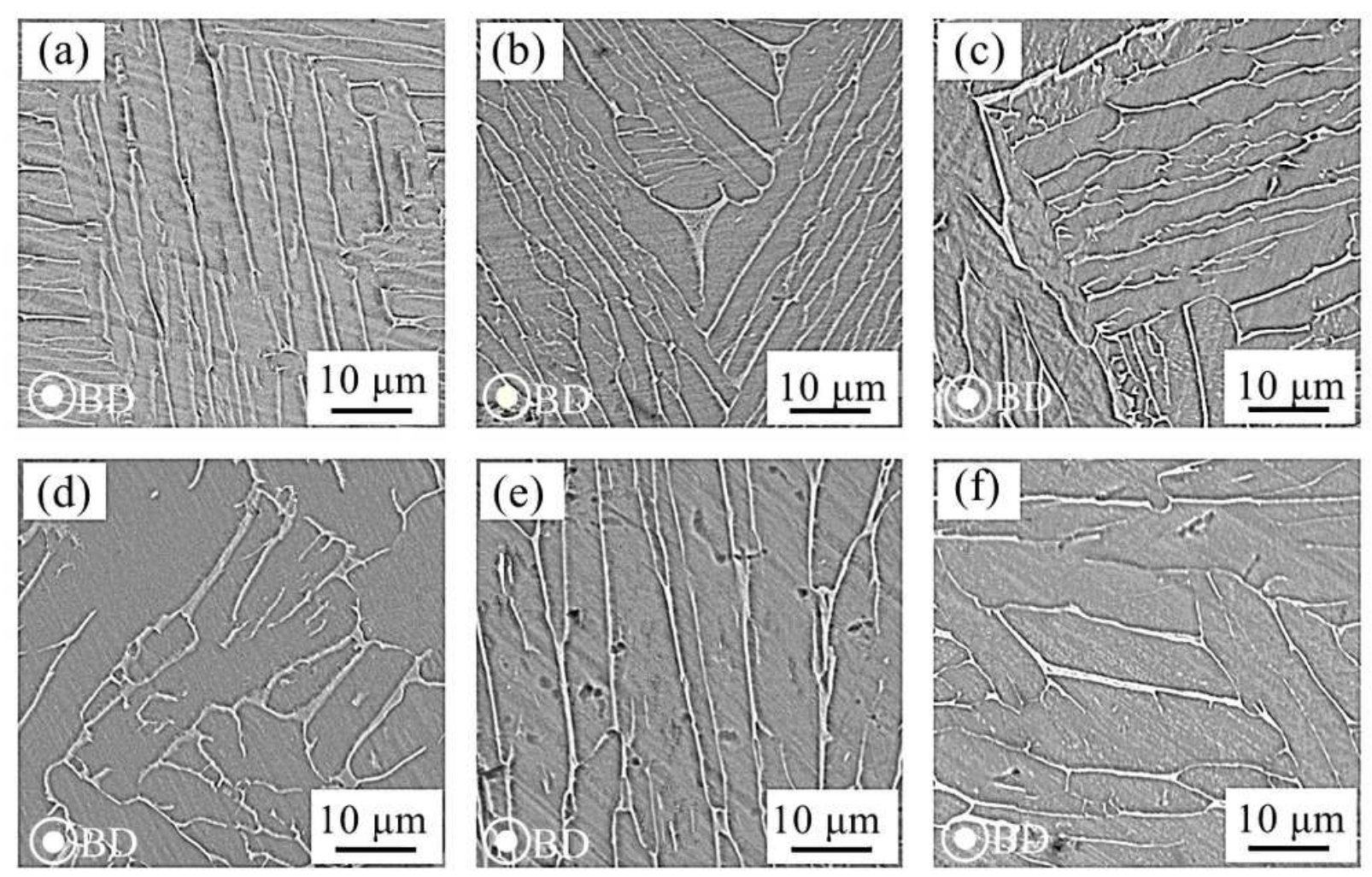

Figure 13

microstructure of (a) I-4 HT1, (b) II-4 HT1, (c) III-4 HT1, (d) I-4 HT2, (e) II-4 HT2 and (f) III-4 HT2 